\title{
Employee perspectives on value realization from data within data-driven business models
}

\author{
Matthias Förster ${ }^{1} \cdot$ Bastian Bansemir ${ }^{2} \cdot$ Angela Roth $^{1}$
}

Received: 5 October 2020 / Accepted: 21 September 2021 / Published online: 2 March 2022

(c) The Author(s) 2022

\begin{abstract}
Firms are innovating data-driven business models (DDBMs) to realize value from data. Yet, making DDBMs work is challenging, and DDBMs often fall short of expected value realization. One reason for this shortfall is that firms do not know how employees, who decisively influence a DDBM's value realization, view this complex and multi-facetted topic. We think it is necessary to understand the employees' perspectives, the dimensions that build these perspectives and the characteristics employees are particularly interested in regarding value realization from data. We address this research gap by applying the Q-methodology to examine the perspectives among 70 employees across twelve DDBMs at a German automotive manufacturer. This yields eight perspectives, e.g., data advocacy, data caution or data practical. By exploring these perspectives, we provide a first groundwork on how employees view and appraise value realization from data which adds to the strive for mastering value realization from data within DDBMs.
\end{abstract}

Keywords Data-driven business models · Value realization from data

JEL classification $\mathrm{L} 62 \cdot \mathrm{O} 32$

\section{Introduction}

In the course of big data and data analytics' technological progress, and the accompanying digitalization of networked businesses (Ngai et al., 2017), data has become a key resource for value realization (Zeng \& Glaister, 2018). Value realization from data is often proceeded and facilitated by data-driven business models (DDBMs). DDBMs are interlocking systems of activities, structures, and processes

Responsible Editor: Christiane Lehrer

Matthias Förster

matthias.f.foerster@fau.de

Bastian Bansemir

bastian.bansemir@bmw.de

Angela Roth

angela.roth@fau.de

1 Chair of Information Systems-Innovation and Value Creation, Friedrich-Alexander University ErlangenNuremberg, Lange Gasse 20, 90403 Nuremberg, Germany

2 Business Development Department, BMW Group, Petuelring 130, 80788 Munich, Germany that constitute rationales for how businesses that are relying on data as their key resource realize economic value (Hartmann et al., 2016). For instance, they propose new and often customized value offerings or create optimized process efficiencies (Schüritz \& Satzger, 2016). Firms have started to innovate and implement DDBMs, inspired by the opportunities to realize additional value through the utilization of available data resources (Hilbig et al., 2020). For instance, DDBMs have discovered a wide range of applications in various industries, such as logistics (Möller et al., 2020), the automotive industry (Seiberth \& Gründinger, 2018), and the energy sector (Chasin et al., 2020). Despite DDBMs' proliferation, firms often fail to seize opportunities to utilize and leverage their data resources or data-analytics capabilities (Günther, 2017a). Firms not uncommonly lag behind their expected value realization (Court, 2015). Due to deficits in value realization, Court (2015) and Ross et al. (2013) have pointed out that some practitioners and academics even question whether any significant value can be realized from data utilization at all (see also Günther (2017a). Despite promising business opportunities, value realization from data is not guaranteed (Ransbotham et al., 2016). In 
short, making DDBMs work remains a challenge for firms (Fruhwirth et al., 2018).

Wiener et al. (2020) identified one reason for this ongoing challenge in the currently limited consideration of stakeholders, who make DDBMs work through their actions and interactions. This limitation particularly applies to the stakeholder group 'employee' who-due to their close integration in a firm and active engagement within a DDBM-provide knowledge, resources, and capabilities and decisively influence the way and extent to which value is realized through their day-to-day operational activities (Freudenreich et al., 2019). Moreover, employees give impetus to push through and implement new business ideas (Gassmann et al., 2016), perform changes of value realization when adapting to changing environmental conditions (Achtenhagen et al., 2013) and establish and alter the relationships to partners and customers and manage their diverse interest. Employees represent a very diverse stakeholder group due to their different functional backgrounds, operational activities in the firm, and various interests according to which they pay special attention (Freeman, 1984; Jones, 1995; Wolfe \& Putler, 2002). Managing these internal stakeholders is a key organizational challenge for DDBMs and for realizing value from data (Fruhwirth et al., 2018). To meet this challenge, we argue that the stakeholder group employees merit closer consideration in research and practice.

An important step in taking a closer consideration is to understand how employees view value realization (Bridoux et al., 2011). These views, which are hereinafter called 'perspectives', provide firms insights on how their employees view and appraise topics - and whether and how they develop varying understandings. Moreover, they provide insights on the employees' opinions and attitudes, as well as the purposes underlying their actions and interactions (Bridoux \& Stoelhorst, 2014; Tikkanen et al., 2005). Understanding the employees' perspectives is, therefore, an essential foundation of avoiding and managing internal discrepancies, challenging possible single-edge ideas (Bittner $\&$ Leimeister, 2014) for value realization, and ensuring that all relevant aspects of value realization are comprehensively considered - for example, data analytics capabilities (Harris, 2012) or customer experience (Barnes et al., 2009; Ugray et al., 2019). Moreover, understanding employee's heterogenous perspectives - their differences, similarities, and synergies-is important to promote innovation and creativity (Kelley \& Littman, 2005). To some extent, understanding these perspectives can even clarify which kinds of internal actors a firm is dealing with within its organization (see also Schymanietz and Jonas (2020)). Given the employee perspectives' importance for value realization, an assumption that these perspectives have already been broadly researched would be reasonable; however, the literature has paid very little attention to specific stakeholders' perspectives.
Particularly in the context of business model (BM) innovation (BMI), this topic remains largely unexplored. Here, the focus is more on how individual cognitive frames and schemas are build according to which stakeholders reflect their BMs (Kringelum, 2015) and decide or act upon (Tikkanen et al., 2005), but how they comprehensively view an issue such as the value rationalization remains uncharted. In taking up this research topic, we aim to understand employees' perspectives on value realization from data by addressing the following research question: What are employee perspectives on value realization from data within data-driven business models?

To answer this research question and investigate employee perspectives, we use the theoretical lens of the stakeholder theory (Freeman, 1984). To unveil and understand the perspectives' subjective inner essences, we use the Q-methodology (QM) according to Stephenson $(1936,1953)$. The QM is a research method that analytically extracts, and clusters shared perspectives on a certain, complex phenomenon and expresses the characteristics of the investigated phenomenon that have high value for the shared perspectives (Cross, 2005). Due to its reliable, structured, easy-to-follow approach (Zabala et al., 2018), the QM has recently gained importance in the BMI research and networked business context (see Moellers et al. (2019)) and it can be effectively applied to organizations to reveal heterogeneous perspectives on business-related issues.

\section{Theoretical background}

This section establishes the theoretical background for the investigation of employee perspectives regarding value realization from data within DDBMs. It outlines the theoretical background on BMs in general, and DDBMs as well as their novelties and value realization characteristics in particular. Following, this section provides a detailed delineation of the currently debated dimension of the multi-facetted and highlevel topic of 'value realization from data within DDBMs'. Understanding these dimensions is crucial for the investigation, as these dimensions found in literature are shaped by the involved stakeholders' viewpoints, concerns, special interests and activities on the one hand, and on the other hand, the discourses about these dimensions bi-directionally surround the stakeholders, and consequently shape the overall perspectives according to which they appraise this topic. An understanding of these dimensions is also important to approach, structure and organize this multi-facetted topic with regards to the investigation. Moreover, this section introduces and explains the stakeholder theory (Freeman, 1984), which serves as the theoretical lens to examine the employees' perspectives. This section also highlights the importance of stakeholder consideration and management 
in DDBM innovation (Fruhwirth et al., 2018; Wiener et al., 2020).

\section{Data-driven business models and value realization from data}

Management attention and research on BMs goes back to the emergence of the internet economy at the turn of the millennium, a landmark shift that forced organizations to adapt their business domains, strategies, and technologies to survive in a new, dynamically changing environment (AlDebei et al., 2008). In this environment, the term $B M$ was prominently introduced by Timmers (1998), who defined a $\mathrm{BM}$ as "an architecture for the product, service and information flows, including a description of the various business actors and their roles; and a description of the potential benefits for the various business actors; and a description of the sources of revenues." (Timmers, 1998, p. 4). Other prominent BM definitions followed, mostly driven by the different lenses that researchers applied. Although no single overarching BM definition has been established to date, the most-cited publications share a common understanding of a $\mathrm{BM}$ as an interlocking system of activities, structures, and processes that constitutes the rationale for how businesses realize economic value (Sorescu et al., 2011).

In the wake of the internet economy, data became increasingly important to improve and further develop BMs-for example, through more efficient communication and internet-based transactions (Afuah \& Tucci, 2003). Given the importance of data and exponential data growth-as well as the ongoing technological progress in data collection, analysis, and processing (Chen et al., 2012)—BMs increasingly relied on data for value realization. So-called DDBMs arose, in which data constitute the key resource for value realization (Hilbig et al., 2020). As evolutionary advancements of BMs (Guggenberger et al., 2020), DDBMs share the ontological similarity and can be defined as interlocking systems of activities, structures, and processes that constitute rationales for how businesses that are relying on data as their key resource realize economic value (Hartmann et al., 2016). The DDBMs' economic value realization is basically achieved through adjustments or renewals to how they: (a) Create value e.g., through data utilization for a cost or productivity optimization of business processes (Cheah $\&$ Wang, 2017) or a renewal of the resource orchestration for value creation (Schüritz \& Satzger, 2016), (b) propose value e.g., by developing new service offerings that provide additional value, such as higher visibilities in logistics (Möller et al., 2020) or safer and more sustainable mobility (Seiberth \& Gründinger, 2018), and (c) capture value e.g., with new kinds of revenue models, such as data subscription or data usage fees (Schüritz et al., 2017). Value realization can be further differentiated into indirect value realization from data, meaning the use of data to optimize businesses e.g., with better decision-making or cost reductions, and direct value realization from data, meaning - for example - the licensed provision of data to external parties for a direct monetary return (data monetization) (Akred \& Samani, 2018; Wixom \& Ross, 2017).

DDBMs and value realization from data have become an important and broadly discoursed topic in academia, with a wide variety of different thematic issues, complementary or opposing subjects of interest and substantive debates. Although the academic discourse is complex and multi-facetted, it can be subdivided into distinct thematical dimensions outlining and comprising the much-discussed issues, which considerably shape the overall discourse on this high-level topic. According to our research these dimensions comprise four items (a-d). (a) The first dimension is the way of realizing value from data within DDBMs. There are two distinctions: direct and indirect value realization (Akred \& Samani, 2018). Direct value realization means receiving a direct monetary return, such as for the licensed provision of data to third parties e.g., for marketing purposes or the development of new products (Akred \& Samani, 2018). Direct value realization is often achieved through specialized market platforms (Fruhwirth et al., 2020a). In the automotive industry, for example, several platforms have been established for data provision and the collaborative development of new, data-driven mobility services (Andria et al., 2016; Pevec et al., 2019). In this context, people are concerned with topics such as ensuring mutual trust among partners, security, and proper data pricing (Spiekermann, 2019). Indirect value realization means using data more implicitly to internally optimize processes. Related topics of interest include achieving higher efficiencies and cost reductions (Wamba et al., 2015; Wixom \& Ross, 2017). (b) The second dimension is the activities and aspects of gathering, processing, and generating valuable data (Baldassarre et al., 2018; Exner et al., 2017). In this context, the use of data analytics to derive unique data insights and realize value is of broad interest and high importance to the involved stakeholders (see Grover et al. (2018), or Seddon et al. (2017)). Data volumes and data qualities are also topics of concern in this regard. Handling enormous data volumes with mostly varying data qualities is very challenging when using data analytics to realize value within DDBMs (Brownlow et al., 2015; Schroeder, 2016). (c) The third dimension essential to perspectives on value realization from data is the tension between the competitive advantage created by data analytics and the potential legal issues of analyzing data. On the one hand, the creative analysis of scarce, firm-unique (customer) data are regarded as an opportunity to generate exclusive data that can ensure the DDBMs' competitiveness (Hagiu \& Wright, 2020; Lambrecht \& Tucker, 2015). On the other 
hand, when using data analytics for individualized customer solutions (McGuire et al., 2012; Wamba et al., 2015), data sensitivity and data protection are crucial topics since the analytical evaluation of data may reveal private and sensible customer information (Schroeder, 2016). Within a given legal scope, firms must be clear about their internal policies to realize value from data within DDBMs (BöhmeckeSchwafert \& Niebel, 2018; Ziegler et al., 2019), and they must weigh possible competitive advantages (e.g., through exclusively generated sensitive customer data) against data sensitivity and protection issues. (d) The fourth dimension is the innovation support via methods and tools for visualization, analysis or the business evaluation of DDBMs (Fruhwirth et al., 2020b) as well as the capabilities to estimate and assess realizable value from data (Engels, 2019; Soley et al., 2018). Research in this context includes methodical artifacts, such as a data insight generator, which establishes links between data and derivable value (Kühne \& Böhmann, 2019), a cost-benefit analysis to evaluate DDBMs' financial impact at an early stage (Zolnowski et al., 2017), or a procedure model for a targeted management of factors influencing the value realization to support a long-term implementation of DDBMs (Förster et al., 2021). Despite methodical approaches, precisely assessing data's realizable value remains difficult, and two different views have emerged on this topic. On the one hand, very positive opinions attribute enormous value potential to data (Nolin, 2019). On the other hand are rather reserved value estimations (Ross et al., 2013). Despite these two different views, consensus suggests that the DDBMs' potential value realization has not yet been fully exploited, and hard work is needed to achieve this benefit (Ransbotham et al., 2016). In this context, firms need new, more competitive capabilities (Bärenfanger \& Otto, 2015) and a strategic push to advance (Bhimani, 2015).

As these dimensions found in literature are grounded on the viewpoints, concerns and special interests of those involved in the value realization from data within DDBMs and also surround and shape how they view and think about this topic, we consider these dimensions being important in this investigation to approach the multi-facetted high-level topic.

\section{Stakeholder theory and data-driven business models}

The stakeholder theory is a theoretical, strategic management approach which considers a firm as a constellation of different stakeholders which realize value by providing knowledge, resources or capabilities and conducting different value realizing activities (Freeman, 1984; Harrison et al., 2010). Managing these stakeholders effectively to achieve the highest possible value realization is a key managerial task (Freeman, 2010). Effective management requires a profound understanding of the stakeholders' engagements and influences on value realization, which, in turn, requires a solid understanding of the stakeholders themselves (Garriga, 2014; Harrison et al., 2010) and their multiple, diverse objectives, interests, and concerns (Donaldson \& Preston, 1995; Foster \& Jonker, 2005; Garriga, 2014). Understanding these objectives, interest and concerns is essential, because they shape the stakeholders' perspectives on topics such as value and value realization (Bridoux et al., 2011; Garriga, 2014) and accordingly their subsequent actions and interactions (Bridoux \& Stoelhorst, 2014; Tikkanen et al., 2005). Thus, the stakeholder theory is a strategic management approach to understand and describe a firms' value realization through considering and effectively using stakeholders who account for actual value realization (Freeman, 1984, 2010).

The stakeholder theory envisions value realization by considering a firm as a network of stakeholders (Harrison et al., 2010). Broadly defined, stakeholders include all actors who influence or are influenced by a firm's strategic undertaking of value realization (Freeman, 1984; Jones \& Wicks, 1999)—for example, customers, suppliers, employees, financiers, and communities (Parmar et al., 2010). Mitchell et al. (1997) established a less macro-dimensional and narrower definition of stakeholders, focusing on the stakeholders with urgency, legitimacy, and power to enforce claims within a firm's value realization undertakings. On the one hand, this latter definition covers-for example-customers, who are becoming more important to value realization in the context of increasingly networked businesses (Pynnönen et al., 2012). On the other hand, it especially focuses on firm-internal, organizational stakeholders, such as employees (Joyce \& Paquin, 2016), who are often regarded as a firm's vital resource (Crane \& Matten, 2004). Mitchell et al. (1997) even attributed a significantly higher influence and power to employees than to other stakeholders due to the employees' close integration in a firm. Hence, employees are tightly engaged in a firm's value realization, providing knowledge, resources, and capabilities and performing operational activities that strongly influence how value is realized (Freudenreich et al., 2019). Moreover, employees make considerable motivational, financial, social, and even geographic commitments to firms (Greenwood \& Anderson, 2009). Thus, they are vigorously concerned with the firms' successes or failures (Maltby \& Wilkinson, 1998). These aspects-especially their close integration and high level of engagement in the value realization-make employees a particularly important stakeholder group that must be understood in more detail when adopting a stakeholder-oriented perspective on value realization. 
A closer look at employees is also interesting since, as a stakeholder group, employees are not only powerful but also very heterogeneous. This heterogeneity is grounded in the employees' potential assignment to different departments and functional backgrounds, performing different work activities accordingly and harboring different opinions, interests, priorities (Freeman, 1984; Jones, 1995), and perspectives (Choi \& Shepherd, 2005; Schwarzkopf, 2006) according to which they judge such (business) matters as a firms' value realization. Moreover, employees can be assigned to different sub-stakeholder groups, such as managers, business owners, or unionists (Greenwood \& Anderson, 2009), according to which they participate in the firms' value realization with different professional roles. In intraorganizational value-realization undertakings some employees even play the roles of internal customers or suppliers (Halis \& Gökgöz, 2007). Although the stakeholder groups' heterogeneity-such as among employees—is apparent, only a few authors have discerned stakeholder groups to be different. Most authors have assumed heterogeneity across stakeholder groups and homogeneity within stakeholder groups, presuming shared opinions, interests, priorities and perspectives for the sake of simplification (Wolfe \& Putler, 2002). That stakeholders within a stakeholder group are different, however, should be taken into account for an accurate and differentiated understanding of stakeholder (Wolfe \& Putler, 2002). Such an understanding is necessary, for example, to avoid conflicts or activities with undesired, onesided consequences on value realization. Such complications are especially prevalent when stakeholder groups, such as employees, differ significantly in their roles, backgrounds, and perspectives, which determine their activities that influence value realization.

An investigation of firm-internal, stakeholder-group employees who are tightly engaged in value realization by providing knowledge, resources, and capabilities and performing operational activities (Freudenreich et al., 2019) encourages an investigation of BMs (e.g., Halsam et al. (2015) or Miller et al. (2014). According to Zott and Amit (2010) BMs comprise stakeholders, such as employees, who perform operational activities and shape the BMs' designs and approaches to value realization. The ongoing research interest in DDBMs has also revealed the important consideration of stakeholders and their influences (e.g., Wiener et al. (2020)), though these elements have not yet been fully understood. To date, knowledge in this regard has included, for example, the work of Günther et al. (2017a, 2017b), who considered stakeholders and the contextual underlying factors that drive and shape their action in their debate on realizing value from data. Other examples are Fruhwirth et al. (2018), who emphasized the importance of proper internal communication and stakeholder management to bring ideas together and inform involved parties-especially during the
DDBMs' implementation and integration - and Kühne and Böhmann (2019), who emphasized the transparency of data usage among involved stakeholders. Overall, the consensus in the DDBM literature suggests that the human factor is essential (Bulger et al., 2014) and stakeholder management greatly important when innovating DDBMs (Fruhwirth et al., 2018; Wiener et al., 2020). Thus, by using the stakeholder theory (Freeman, 1984) as the theoretical lens to investigate employee perspectives on value realization from data, we build upon the literature's consensus regarding future DDBM research to focus more on the DDBM stakeholders as they influence and perform value realization.

\section{Research design}

We chose the Q-methodology (Stephenson, 1936, 1953) as the appropriate research method for this investigation due to its structured way to analytically and reliably explore shared employee perspectives on value realization from data within DDBMs, and to qualitatively express their different characteristics regarding the complex and multi-facetted issue (see Zabala et al. (2018)).

The following section presents the QM, outlines the data selection and collection and describes the three-phased data analysis process used to examine employee perspectives on value realization from data.

\section{Research method}

Using the QM (Stephenson, 1936, 1953), our investigation aims to answer the research question to unveil employee perspectives on value realization from data within DDBMs. The QM is a research method that aims to explore the subjective inner essence of shared opinions, attitudes, or perspectives on complex phenomena by analytically expressing which certain characteristics of the investigated phenomenon have value and significance within which group of shared perspectives (Stainton Rogers, 1995; Watts \& Stenner, 2005). This approach is performed by linking quantitative features, such as an inverted multivariate factor analysis (Sell \& Brown, 1984), with qualitative features, such as subsequent interviews (Stephenson, 1953; Zabala, 2014). By combining qualitative and quantitative features, the $\mathrm{QM}$ provides profound evidence and new insights - beyond separate qualitative or quantitative methods - and it can best be described as a 'semi-quantitative' (Zabala, 2014) or 'qualiquantilogical' research method (Watts \& Stenner, 2003). The QM follows a structured analytical process (Brown, 1980) centered around a heterogeneous, multi-element set of statements ( $q$ set), expressing formerly investigated contentions regarding an investigated phenomenon (Watts \& Stenner, 2005). 
Next, this $q$-set is sorted ( $q$-sorting) by the interviewees. The resultant statement configurations ( $q$-sorts) are quantitively factor-analyzed and qualitatively analyzed by post- $-q$-sort interviews to reveal perspectives among the interviewees and interpret the perspectives' inner essences (Stainton Rogers, 1995; Watts \& Stenner, 2005; Zabala, 2018).

Compared to other research methods, one clear strength of the QM is that it is easy to follow due to its clearly structured and analytical approach, yet it allows to openly address latent or undisclosed views (Mazur \& Asah, 2013) that interviewees would rather not articulate via purely qualitative research methods. Moreover, according to Zabala et al. (2018) the QM is effectively applicable to a relatively small sample of interviewees. This characteristic favors its intraorganizational use in uncovering diverse, frequent and nonfrequent perspectives-in case of this study, employee perspectives on value realization from data within DDBMs.

\section{Data selection and collection}

\section{Data Selection}

Altogether, across the three QM analysis phases, we selected 19 DDBMs and analyzed them to reveal employee perspectives on value realization from data (see Fig. 1). 14 of these 19 DDBMs involved a German automotive manufacturing firm, which constitutes the empirical main setting. The other five DDBMs were from the telecommunication, information technology, education, retail, and finance industries and were included for external validity within the $Q M$ refinement \& pre-test phase. A German automotive manufacturing firm was chosen as the empirical main setting because, due to the automotive industry's ongoing digitalization (Grieger \& Ludwig, 2019; Hanelt et al., 2015) manufacturing firms must rethink, adapt, and refine former product-centric BMs, such as vehicle production, and build novel, more servicecentric DDBMs, such as digital mobility services or data service platforms (Hanelt et al., 2015). For this business transformation, automotive manufacturing firms require additional expertise on the DDBMs' development (Piccinini et al., 2015) and value realization from data (Mohr et al., 2016; Soley et al., 2018). This situation of requiring and building up new expertise represents an interesting research opportunity, as in this early stage of business transformation, employees form their perspectives regarding value realization from data, and their perspectives remain diverse and mainly unharmonized (e.g., due to years-long business experiences). Understanding these heterogenous perspectives promises interesting findings for research. In practice, understanding these perspectives is an essential success factor for stakeholder management (Fruhwirth et al., 2018; Wiener et al., 2020) and expertise in DDBM innovation
(Hanelt et al., 2015). For example, when an understanding of these perspectives avoids internal departmental discrepancies and ensures that all relevant aspects of value realization are considered within the innovation of DDBMs. Therefore, a manufacturing firm in the automotive industry represents an interesting research opportunity.

The purposeful selection of the 19 DDBMs was conducted according to the following criteria. First, each DDBM represents a new type of business venture for firms. Second, data are the key resources for each DDBM's value realization e.g., for new kinds of customized, data-driven services and product offerings (Fielt et al., 2019), analyticsas-a-service businesses ventures (Hartmann et al., 2016; Schroeder, 2016), or data provision services (Akred \& Samani, 2018; Wixom \& Ross, 2017). Third, there was sufficient access to archival records (emails, presentations, and DDBM documents), as well as interviews and conversations. Figure 1 displays the DDBM data selection across the three QM analysis phases. For competitive reasons, the DDBMs and their data usage cannot be explained in more detail, so the DDBMs are described in a generalized manner instead.

Within the QM development phase, we selected three DDBMs (DDBMs 1-3) to initially examine and understand the dimensions of the multi-facetted topic of 'value realization from data within DDBMs' from the practical context of the employees' daily operations. Within the $Q M$ refinement and pre-test phase, six automotive DDBMs (DDBMs 1-6) and five DDBMs outside the automotive industry (DDBM 7-11) were investigated. DDBMs 7-11 were deliberately chosen for two reasons: first, to avoid the intra-industry biases of the methodical research design (e.g., within the $q$ set) to ensure higher reliability and validity in the later QM examination, and second, to verify the cross-industry objectivity, relevance, and transferability of the QM findings. The final QM execution phase contains DDBMs 1-3 and nine other automotive DDBMs (DDBMs 12-19) to derive and examine perspectives on value realization from data.

Since a DDBM's value architecture and purpose, as well as the form of its value-oriented data processing, influence perspectives regarding value realization from data-and since this investigation particularly aims to explore the differences and similarities between these perspectives - the twelve DDBMs of the QM execution phase were clustered in advance into four QM execution clusters (A-D). To form these clusters, the twelve DDBMs were scrutinized according to the following aspects of value realization from data: (a) the DDBMs' main design, purpose, and their forms of value architecture and data processing (Exner et al., 2017; Hartmann et al., 2016) as well as degree of business renewal (Breitfuß et al., 2019; Schüritz \& Satzger, 2016); (b) the nature of their data usage to realize value (Becker, 2016; Wamba et al., 2015; Woerner \& Wixom, 2015); and (c) the dynamic market and business implications of value 


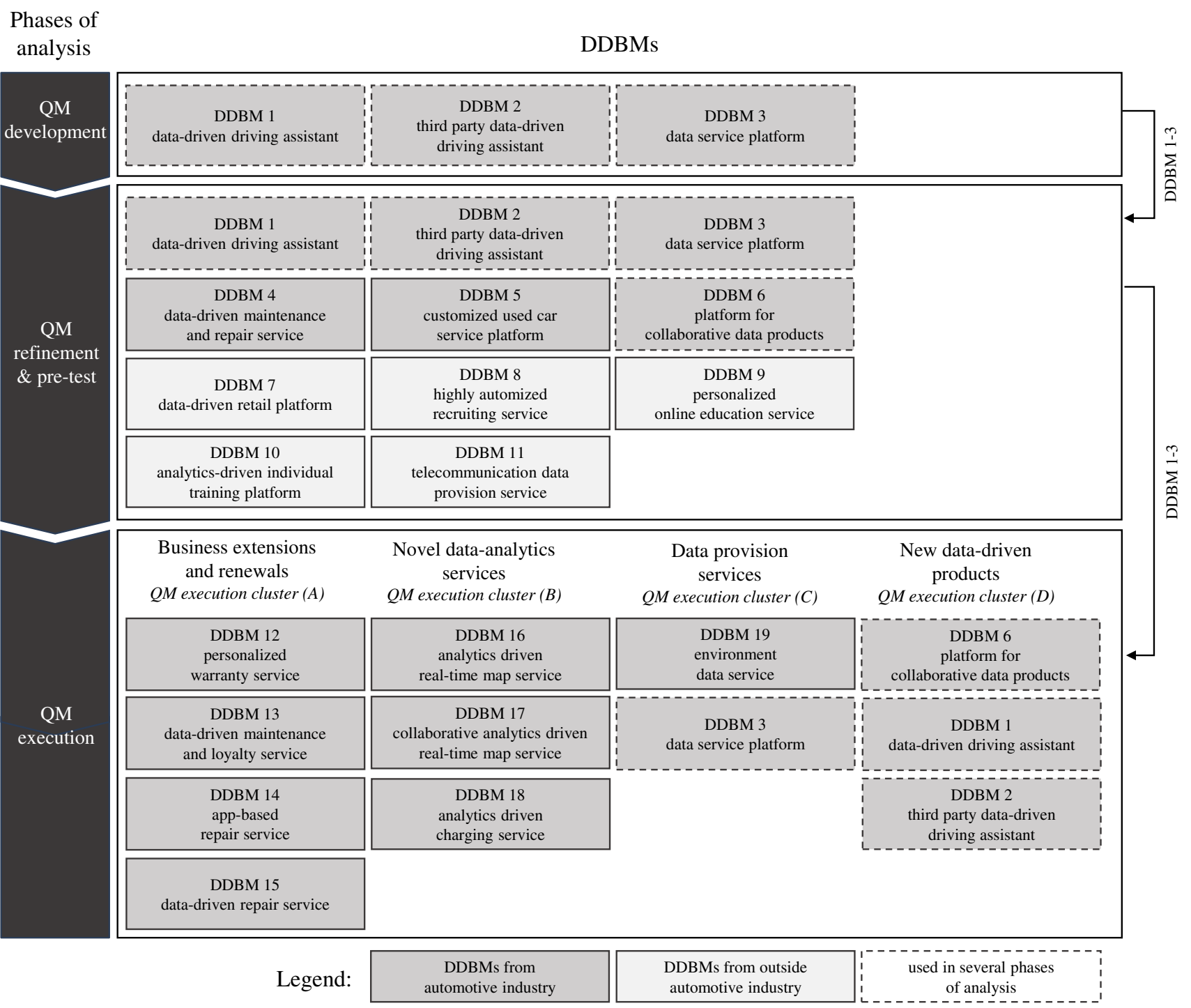

Fig. 1 Q-methodology data selection

realization from data (El Sawy \& Pereira, 2013; Förster et al., 2019; Zhang et al., 2015). Grounding on these aspects, the twelve DDBMs of the QM execution phase were clustered as follows:

Cluster (A) - business extensions and renewals: this cluster comprises DDBMs in which data are used to extend and renew existing BMs in the field of after-sales services in order to make after-sales more personalized, and thus realizing additional value. These DDBMs include, for example, a data-driven maintenance and loyalty service and a personalized warranty service.

Cluster (B)—novel data analytics services: this cluster comprises novel DDBMs in which data analytics are an integral part of realizing value - whether to develop a (collaborative) analytics-driven, real-time map service or to provide an analytics-driven charging service.

Cluster (C)—data provision services: this cluster comprises DDBMs in which anonymized data-as-a-service solutions are made accessible via a corporate platform and provided to business partners for a monetary return. Cluster (D)—new data-driven products: this cluster comprises DDBMs based on new, data-driven products for which continuous data generation and processing are essential (e.g., a data-driven driving assistant).

Summarizing, we clustered the twelve DDBMs from the $Q M$ execution phase according to their design and value architecture for value realization in order to highlight the differences and commonalities between the QM findings. This clustering led to strong QM findings within one cluster, 
yet comparable findings between the clusters. A group of two DDBM practitioners and two researchers conducted the clustering.

\section{Data collection}

The following data types were collected: (a) archival records, including DDBM roadmaps, canvases, data documents, interim and final presentations, emails, and other DDBMrelated artefacts; (b) 90 interviews with employees from the selected DDBMs; (c) interview transcripts and memos; (d) observations from meetings and internal discussions; (e) 90 $q$-sort exercises within the three QM phases; and (f) a literature review, involving an extensive internet recherche of the academic and practical dimensions of the topic "value realization from data within DDBMs'. To ensure the investigational rigor, the data types were constantly triangulated (Flick, 2011).

For a holistic QM examination, we interviewed employees from different departments and international subsidiaries who had different functional, organizational, and hierarchical backgrounds. These interviewees were categorized into the following four functional categories: business and IT (to consider both business and technical backgrounds), strategy (to consider strategic backgrounds alongside more operational backgrounds), and DDBM lead (a superordinate category of managers who undertake business-owner tasks independent from their profession). We conducted the categorization for later reflection and discussion of the eight perspectives identified in the QM examination. In total, 90 interviews were conducted during the three analysis phases. Within the QM development phase, eleven open interviews aimed to uncovering and collecting content-related characteristics and issues that practitioners pay special attention to or are of particular interest to them in their daily operations and significantly shape their perspective regarding value realization from data within DDBMs. In addition, these interviews aimed to enrich and complement the knowledge from the literature so that we have a comprehensive view and clear structure along five thematic dimensions that summarize the academic and practical viewpoints, and discourses to investigate employee perspectives on value realization from data.

As an integral part of the $Q M$ refinement and pre-test phase, another five open interviews and 14 post- $q$-sort interviews were conducted. Moreover, 58 post- $q$-sort interviews were conducted within the QM execution phase. These interviews aimed for an enhanced understanding and qualitative interpretation of the findings from the QM factor analyses.

\begin{tabular}{|c|c|c|c|c|}
\hline $\begin{array}{l}\text { Phases of } \\
\text { analysis }\end{array}$ & $\begin{array}{l}\text { Objectives of } \\
\text { analysis }\end{array}$ & $\begin{array}{c}\text { Data } \\
\text { collection }\end{array}$ & $\begin{array}{l}\text { Outcomes of } \\
\text { analysis }\end{array}$ & $\begin{array}{l}\text { Quality assurance measures (M) } \\
\text { \& quality objectives }(\mathrm{O})\end{array}$ \\
\hline $\begin{array}{c}\text { QM } \\
\text { development }\end{array}$ & 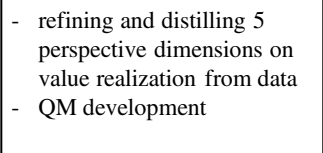 & $\begin{array}{ll}\text { - } & \text { literature review } \\
- & 11 \text { open interviews } \\
- & \text { archival records } \\
- & \text { qualitative observations }\end{array}$ & $\begin{array}{l}5 \text { dimensions of value } \\
\text { realization from data }\end{array}$ & $\begin{array}{l}\text { - triangulation of data sources }(\mathrm{M}) \text { for the construct } \\
\text { validity and operationalization of the QM }(\mathrm{O}) \\
\text { - two iterative interview cycles }(\mathrm{M}) \text { for the } \\
\text { internal, logical validity and the consistency of } \\
\text { QM }(\mathrm{O})\end{array}$ \\
\hline $\begin{array}{c}\mathrm{QM} \\
\text { refinement } \\
\text { \& pre-test }\end{array}$ & \begin{tabular}{|l} 
- \\
refinement and finalization \\
of the QM design \\
- \\
pre-testing with industry- \\
external firms for avoiding \\
inter-firm and inter-industry \\
biases of the QM design \\
- \\
checking relevance and \\
transferability of the QM \\
- \\
pre-testing for QM \\
applicability and reliability
\end{tabular} & $\begin{array}{l}\text { - } 5 \text { open interviews } \\
\text { - } 14 \text { post q-sort interviews } \\
\text { - } 18 \text { q-sort exercises } \\
\text { - } \quad \text { archival records } \\
\text { - } \quad \text { literature review }\end{array}$ & $\frac{\text { final QM statements }}{\text { final QM design }}$ & $\begin{array}{l}\text { industry-external interviews with DDBM experts } \\
\text { from practice and science (M) for avoiding inter- } \\
\text { industry biases of the QM and ensuring the } \\
\text { generalizability of the QM findings (O) } \\
\text { - checking QM quality criteria (see appendix II.) } \\
\text { (M) for the quantitative applicability and validity } \\
\text { of the QM (O) }\end{array}$ \\
\hline \multirow{2}{*}{$\begin{array}{c}\mathrm{QM} \\
\text { execution }\end{array}$} & 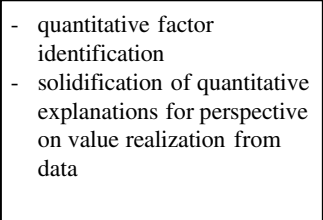 & $\begin{array}{l}\text { - } 58 \text { post q-sort interviews } \\
\text { - } 70 \text { q-sort exercises }\end{array}$ & $\begin{array}{c}11 \text { factors from } \\
\text { q-method analysis } \\
\text { (quantitative findings) }\end{array}$ & $\begin{array}{l}\text { - } 4 \text { factor-test analyses (2-5 numbers of factors) (M) } \\
\text { for the identification of factors with the highest } \\
\text { significance, congruence and percentage of } \\
\text { explained variance }(\mathrm{O}) \\
\text { - checking QM quality criteria (see appendix II.) } \\
\text { (M) for the quantitative applicability and validity } \\
\text { of the QM }(\mathrm{O})\end{array}$ \\
\hline & $\begin{array}{l}\text { - qualitative interpretation } \\
\text { and understanding of the } \\
\text { quantitative findings } \\
\text { - distillation of eight } \\
\text { perspectives on value } \\
\text { realization from data }\end{array}$ & 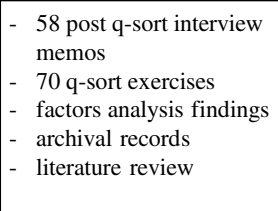 & $\begin{array}{l}8 \text { perspectives on value } \\
\text { realization from data } \\
\text { within DDBMs } \\
\text { (qualitative findings) }\end{array}$ & $\begin{array}{l}\text { comparisons of statement positioning, } \\
\text { significances and factor loadings (M) for the } \\
\text { quantitative applicability and validity of the QM } \\
\text { findings }(\mathrm{O}) \\
\text { - literature review on academic and practical } \\
\text { dimensions of perspectives }(\mathrm{M}) \text { for ensuring the } \\
\text { novelty and contribution of the QM findings }(\mathrm{O})\end{array}$ \\
\hline
\end{tabular}

Fig. 2 Q-methodology analysis process 
We conducted the interviews in person or via Skype, and they lasted between 45 and $90 \mathrm{~min}$. During these interviews transcripts, memos, and-if permitted-audio recordings were conducted.

\section{Data analysis}

This section outlines the QM analysis process. Figure 2 displays the three-phase data analysis process, highlighting the analysis objectives and outcomes while showing the collected data types, as well as the quality assurance measures and objectives, for each phase of this process.

\section{QM development}

The analysis started with a literature review on the topic of value realization from data within DDBMs and the main dimensions of the current academic discourse in this regard. This was a decisive first step to uncover anchor points with which to approach and examine perspectives toward this topic. Afterward, we conducted in-depth examinations of DDBMs 1-3 with eleven open interviews (see Appendix A) and an archival-record analysis. This step aimed to identify, adapt, refine, and subsequently distill five academic and practical dimensions regarding the topic of DDBMs and value realization from data according to which we intend to structure the research on employee perspectives. Triangulation (Flick, 2011) ensures a high construct validity and the operationalization of the distilled five dimension. The final five academic and practical dimensions (see Table 1) thematically comprise:

- The applied way of value realization, with its two main distinctions-direct value realization from data and indirect value realization from data (e.g., Wixom and Ross (2017))

- The focus of value realization, with its two main distinctions - focus on valuable data generation 'data value' and focus on generating 'business value' by using data (e.g., Akter and Wamba (2016) or Grover et al. (2018))

- The question of data resource competitiveness, especially data exclusivity (e.g., Lambrecht and Tucker (2015))

- The ability to estimate the value realization potential, for example in business cases (e.g., Soley et al. (2018))

- The competitiveness of the current competitive DDBM capabilities, especially strategic and organizational setup to realize value from data within DDBMs (e.g., Ghoshal et al. (2014))
Based on these five dimensions, we created a heterogeneous set of QM statements, expressing contentions regarding the studied phenomenon (Watts \& Stenner, 2005). To better understand and practically manage the interview statements, these statements were deliberately formulated into simple and rather practical wording, such as 'making money with data' instead of 'value realization from data' or 'data licensing' instead of 'direct value realization through licensed data monetization'. According to the qualitative data analysis procedure by Gioia et al. (2012) we created the statements using open coding. By doing so, we refined the interviews and literature's first-order concepts on the dimensions to second-order themes to reveal the initial 50 QM statements. In another coding cycle, the 50 QM statements were condensed into $25 \mathrm{QM}$ statements, whereas five statements related to one dimension. Table 1 shows the final 25 statements ( $q$-set), including the corresponding literature and interview-partner categories, which decisively indicated the statements' formulation.

\section{QM refinement \& pre-test}

The QM pre-test aimed to refine the QM design and ensure the applicability of the 25 statements, as well as the plausibility of the methodological approach. In the pre-test, we asked 18 interviewees from eight DDBMs (DDBMs 4-11) to perform the $q$-sorting, a self-referential process (Ramlo \& Newman, 2011) based on the criteria of agreement and disagreement with the statements. This testing involved placing cards (each displaying one statement) on a triangular-shaped sheet, constituting a fixed quasi-normal distribution (Stainton Rogers, 1995). This task required the interviewees to reflect on ranking each statement compared to each other statement. Such sorting leads to creative combinations of statement configurations ( $q$-sorts), expressing the interviewees' perspectives. In order to avoid intra-industry biases and to verify the findings' industry objectivity, relevance, and generalizability industry-external views (DDBMs 7-11) were integrated. Moreover, to ensure the statements and the QM approach's viability, and the performability of the factor analyses (Watts \& Stenner, 2005) post-q-sort interviews were conducted. To assure quantitative quality we relied the investigation on the following QM factor characteristics: $n$-factor loadings, standard errors, reliability, and explained variability (see Appendix C). The RStudio package ' $q$-method' (Zabala, 2014) calculated these factor characteristics. 


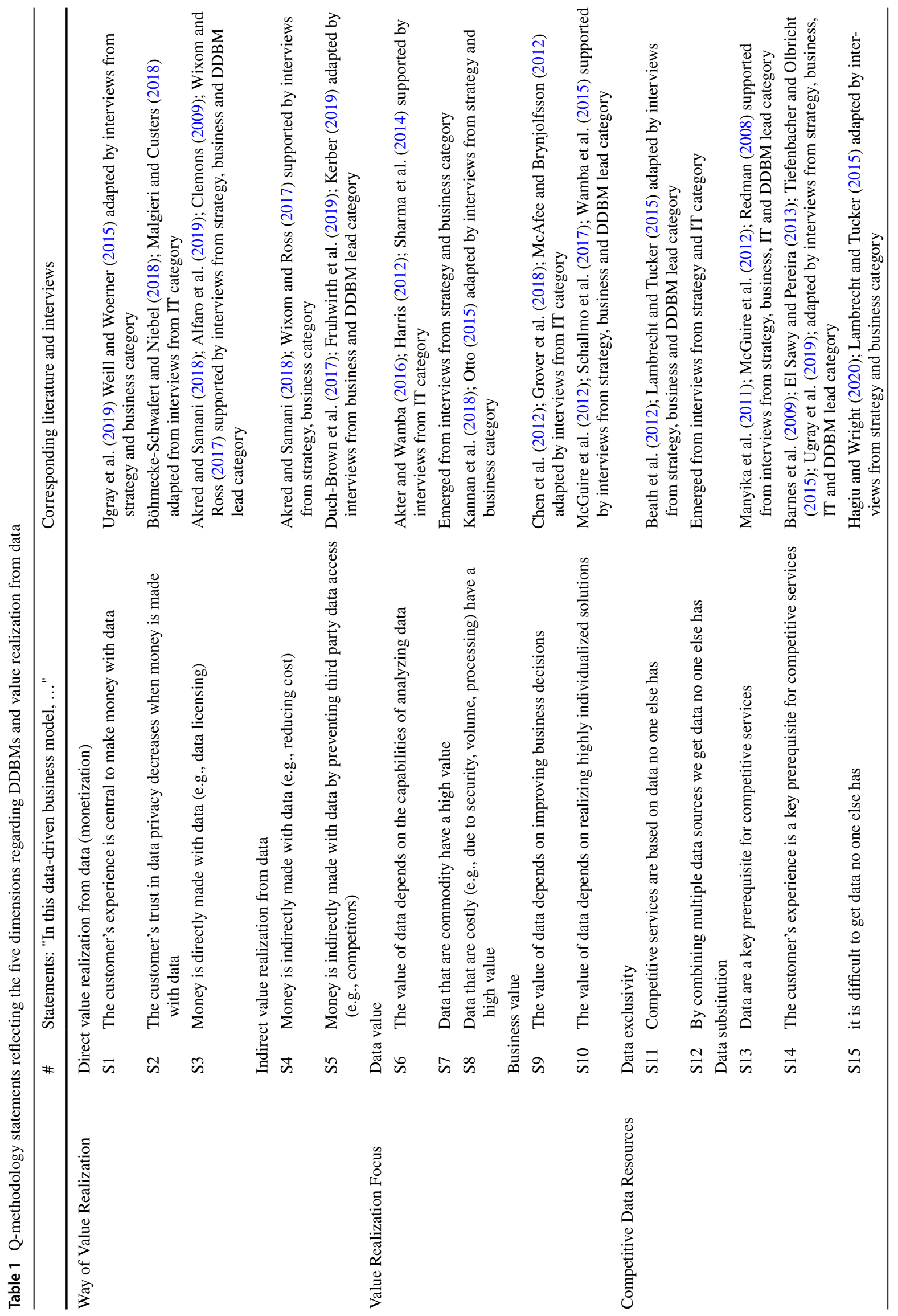




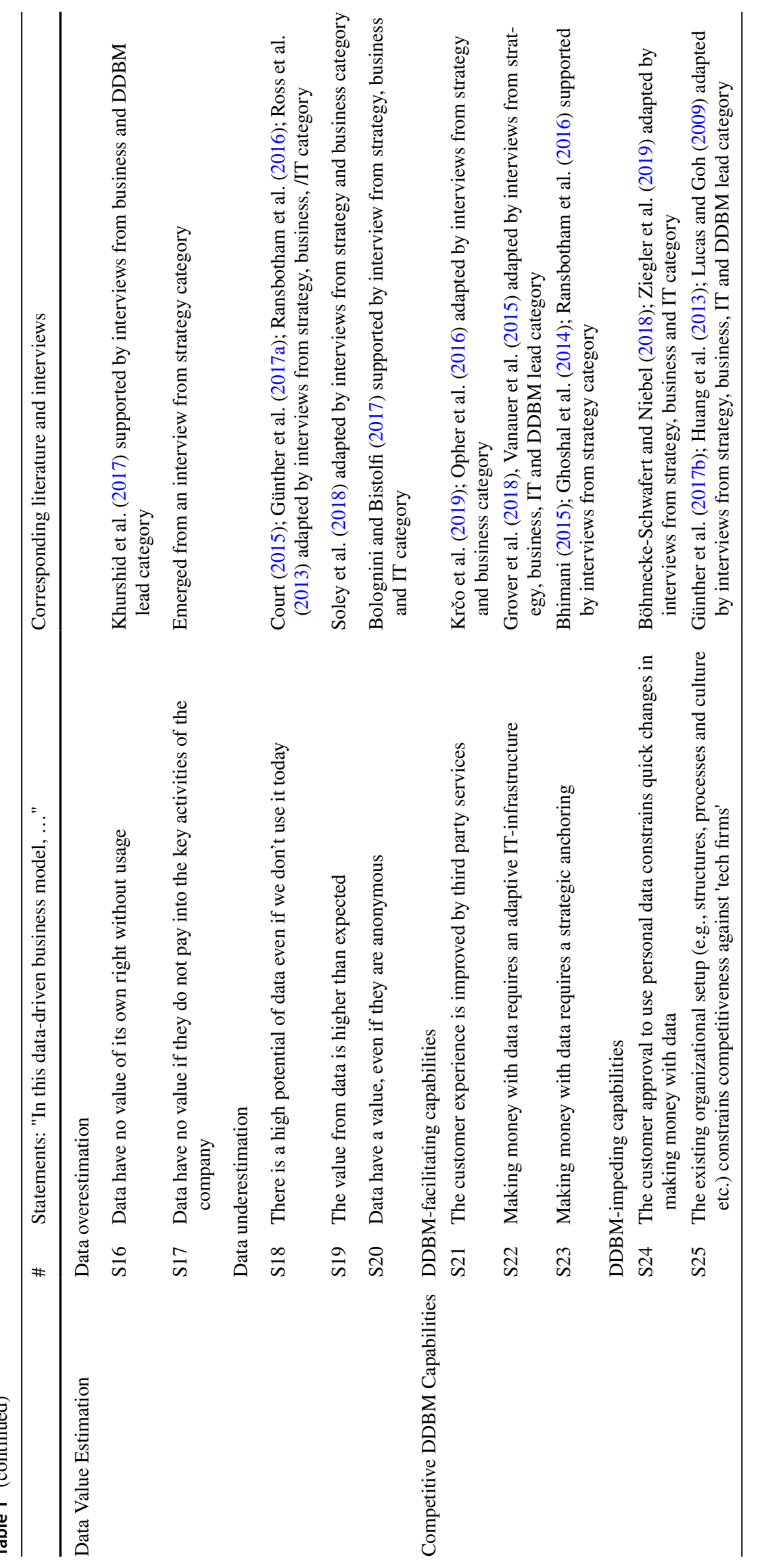




\section{QM execution}

The QM was conducted by asking 70 interviewees from twelve DDBMs to perform the $q$-sorting (see Appendix B). In line with the four QM execution clusters, a QM analysis for every cluster was conducted. The QM reduced the 70 $q$-sorts, via factor rotation 'varimax' and principal component analysis, into two to three factors within each cluster (Stephenson, 1936, 1953; Zabala, 2018). The decision on the number of factors based on three different factor analyses per cluster, aiming to identify the optimal number of factors with the highest significance and eigenvalue and the highest congruence and percentage of explained variance (see Appendix C). The statement factor loadings and $z$-scores of the eleven QM factors comprise shared perspectives regarding the $q$-sort statements on a quantitative level. Grounded on the $q$-sort transcripts and memos, we qualitatively interpreted the eleven factors and distilled them into eight distinct perspectives.

\section{Findings}

This section outlines and describes the QM findings. First, the multivariate factor analyses reduced the ratings of the 25 statements to eleven definable QM factors. Each QM factor characterizes distinct congruences and percentages of explained variance regarding the 25 statements in its group of interviewees. Moreover, each QM factor characterizes distinct factor loadings ( $z$-scores) and normalized $z$-scores. These $z$-scores, as weighted average scores of the $25 q$-sort statements, display the ratings of the randomly distributed statements to discern agreement and disagreement with each statement. The normalized $z$-scores, as integer approximations of the $z$-scores, describe how a group of interviewees who shared similar perspectives had rated the statements (Zabala, 2014; Zabala et al., 2018), from -4 (totally disagree) to +4 (totally agree). Table 2 displays both $z$-scores and normalized $z$-scores for the eleven QM factors.

Grounded on the eleven QM factors, we analyzed and interpreted the $q$-sort transcripts and memos and condensed the eleven QM factors into eight perspectives on value realization from data among the 70 interviewees. These employee perspectives are best described by the following hypernyms, presented in alphabetical order: data advocacy $\left(\mathrm{f} 1_{\mathrm{B}}\right)$, data business mediation $\left(\mathrm{f} 2_{\mathrm{B}}\right)\left(\mathrm{f}_{\mathrm{C}}\right)$, data caution $\left(\mathrm{f} 1_{\mathrm{A}}\right)$, data collaborative $\left(\mathrm{f}_{\mathrm{B}}\right)\left(\mathrm{f}_{\mathrm{D}}\right)$, data customer-reflective $\left(\mathrm{f} 2_{\mathrm{D}}\right)$, data customization $\left(\mathrm{f} \mathrm{3}_{\mathrm{A}}\right)$, data indecisiveness $\left(\mathrm{f} \mathrm{f}_{\mathrm{A}}\right)$ and data practical $\left(\mathrm{f} 1_{\mathrm{C}}\right)\left(\mathrm{fl}_{\mathrm{D}}\right)$. In the following subsections, the eight employee perspectives are explained in detail, based on statement-level characterizations.
Table 3 summarizes the eight perspectives by presenting the main characteristics of the perspectives in more detail using the QM statement factor loadings (see Table 2) and the main characteristics in regard to the overall statement ratings along the dimensions. To show the perspectives' similarities but also highlight their differences regarding the thematic dimensions, we have inserted graphical illustrations in the form of spider diagrams.

\section{Data advocacy perspective}

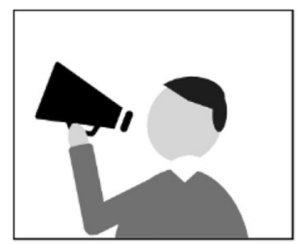

Inspired by the technical and value realization potentials of data, the data advocacy perspective optimistically considers and promotes data value realization efforts. It aims for having pertinent analyzing capabilities $\left(\mathrm{f} 1_{\mathrm{B}}: 1.37, \mathrm{~S} 6\right)$ to gain valuable data that reveal customer insights. Enriched data e.g., through the combination of multiple data sets ( $\mathrm{f}_{\mathrm{B}}$ : $0.93, \mathrm{~S} 12)$ is viewed as exclusive resources and prerequisites for competitive services $\left(\mathrm{f} 1_{\mathrm{B}}: 0.88, \mathrm{~S} 11\right)\left(\mathrm{f} 1_{\mathrm{B}}: 0.89, \mathrm{~S} 13\right)$. Employees with a data advocacy perspective estimate extensive future potential of consistently analyzed and combined data sets, and advocating for active data usage $\left(\mathrm{fl}_{\mathrm{B}}: 1.27\right.$, S16) (f1 $\left.1_{B}: 1.78, \mathrm{~S} 18\right)$. Such future potentials are also estimated for anonymous data $\left(\mathrm{f}_{\mathrm{B}}: 1.59, \mathrm{~S} 20\right)$. Since DDBM 16 for example, is an analytics-driven, real-time map service grounded on geodata, an individualized solution $\left(\mathrm{f} 1_{\mathrm{B}}\right.$ : $-0.43, \mathrm{~S} 10)$ and an associated need for a high-level customer experience in order to offer a competitive service $\left(\mathrm{f} 1_{\mathrm{B}}\right.$ : $-0.84, \mathrm{~S} 14)$ or make money $\left(\mathrm{f} 1_{\mathrm{B}}:-1.20, \mathrm{~S} 1\right)$ is rated rather low by employees who adopt this perspective. Moreover, since this service is based on anonymous geodata, it entails no need to constantly obtain customer consent for evolutionarily adapted data usage $\left(\mathrm{fl}_{\mathrm{B}}:-1.12, \mathrm{~S} 24\right)$ and data privacy $\left(\mathrm{f} 1_{\mathrm{B}}:-1.20, \mathrm{~S} 2\right)$. This perspective aims neither for direct value realization from data via licensing $\left(\mathrm{f}_{\mathrm{B}}:-0.21, \mathrm{~S} 3\right)$ nor for indirect value realization from data $\left(\mathrm{f} 1_{\mathrm{B}}:-1.10, \mathrm{~S} 4\right)$ $\left(\mathrm{f} 1_{\mathrm{B}}:-1.51, \mathrm{~S} 5\right)$. To ensure enthusiastic experimentation with data, strategic anchoring $\left(\mathrm{fl}_{\mathrm{B}}: 0.88, \mathrm{~S} 22\right)$ is necessary. Existing organizational setups do not entirely allow for thorough data usage $\left(\mathrm{fl}_{\mathrm{B}}: 0.91, \mathrm{~S} 25\right)$. Summarizing, the data advocacy perspective describes the 'enthusiastic techie way' of viewing value realization from data, focusing on creating valuable, exclusive data for technical, potential-oriented usage. 


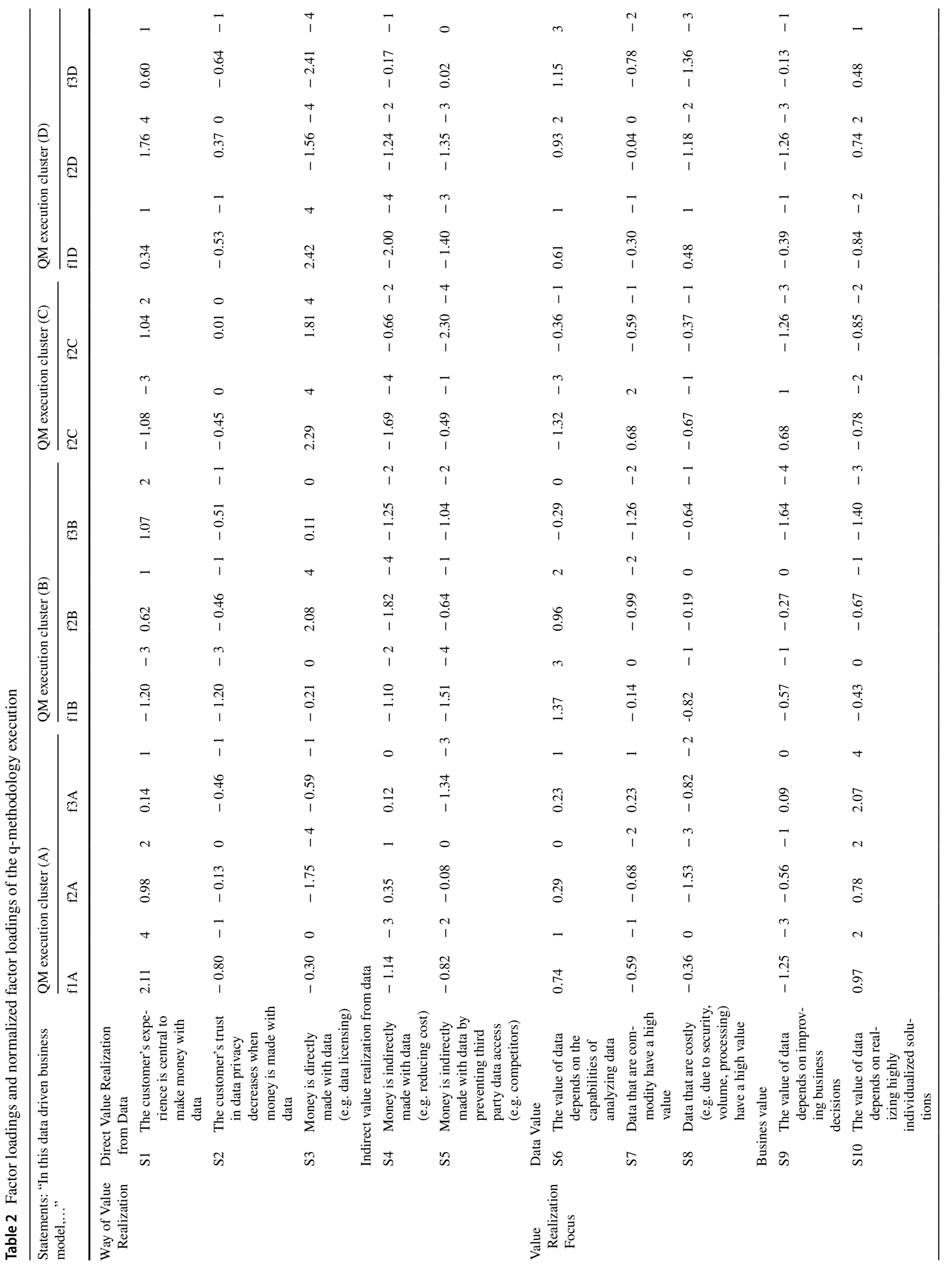




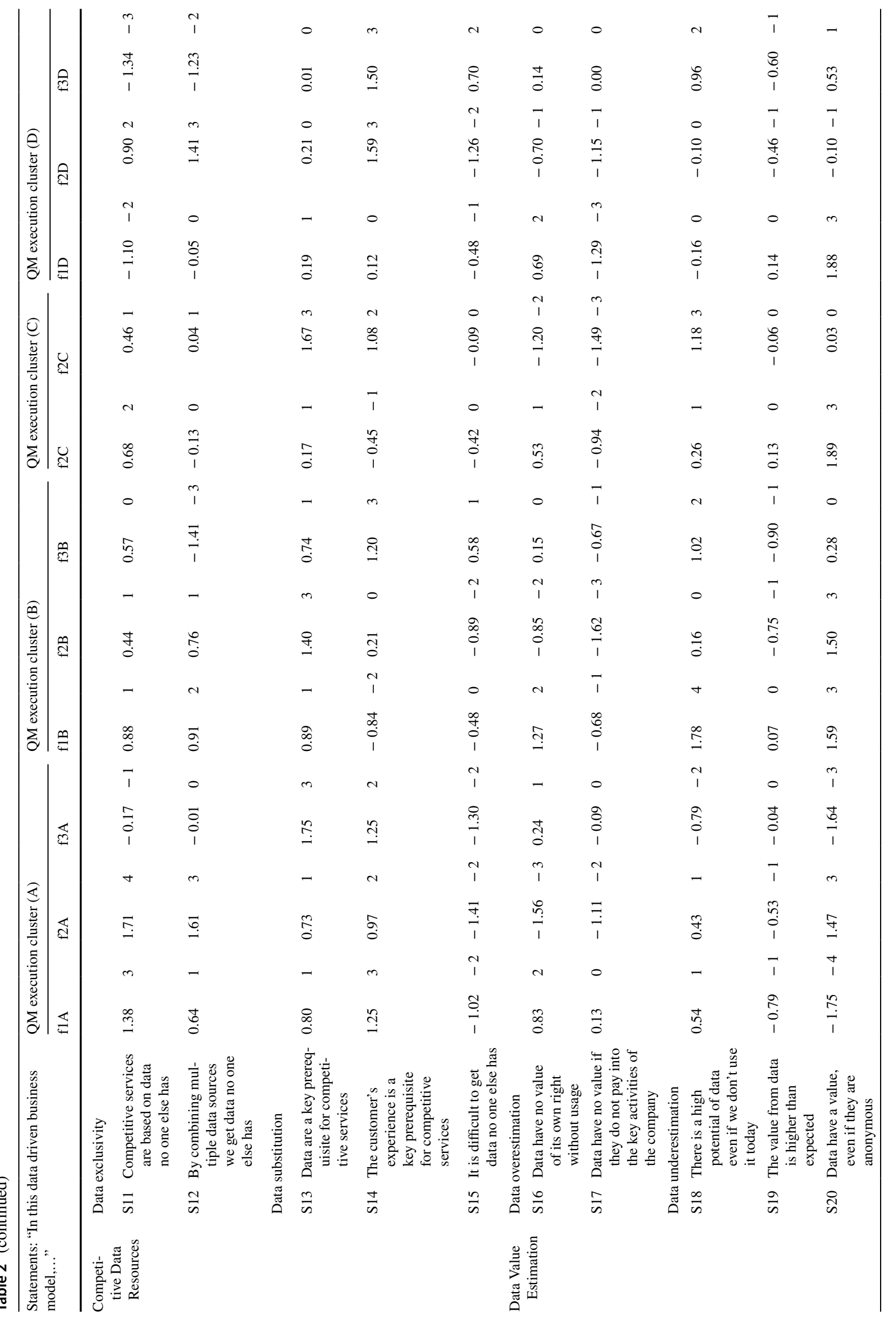




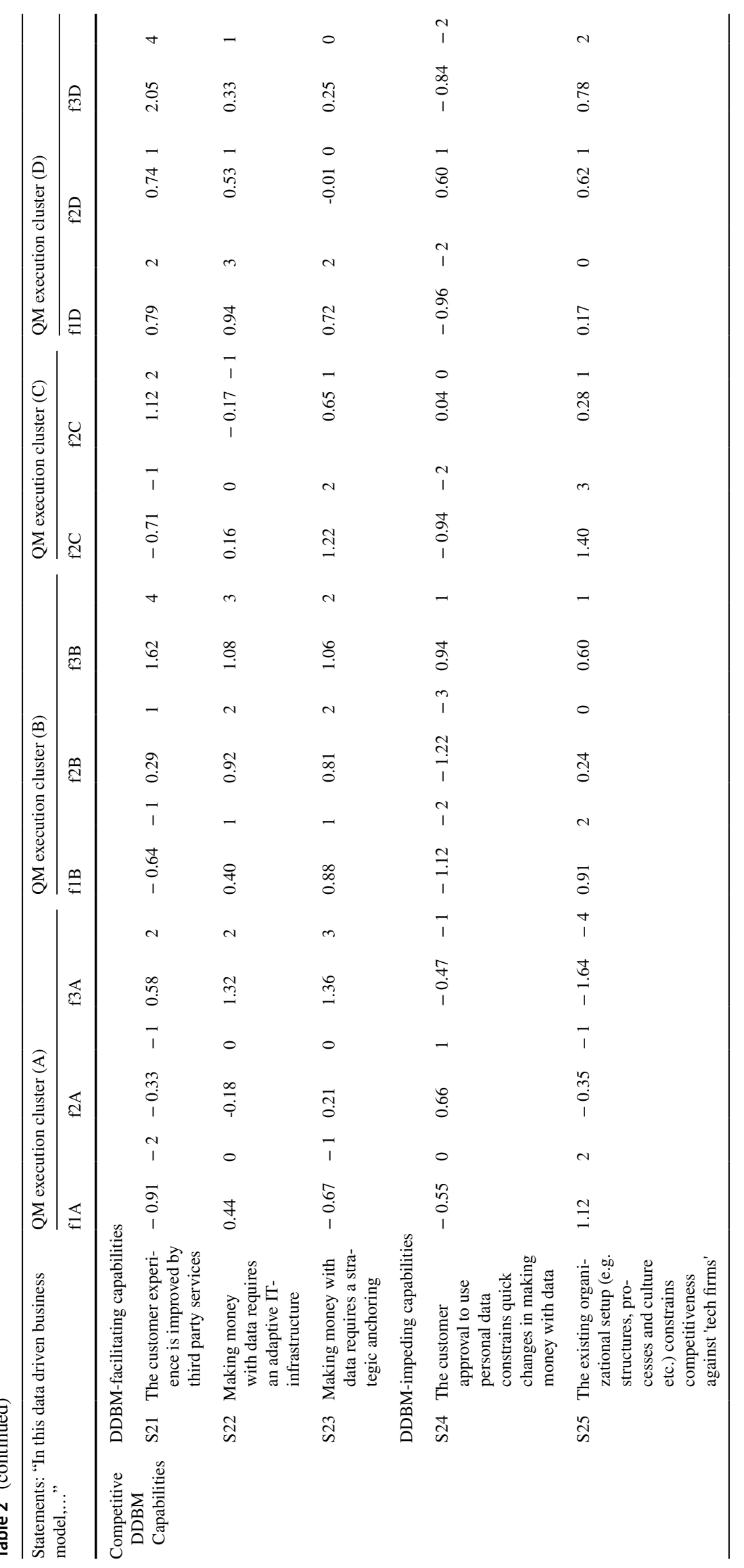




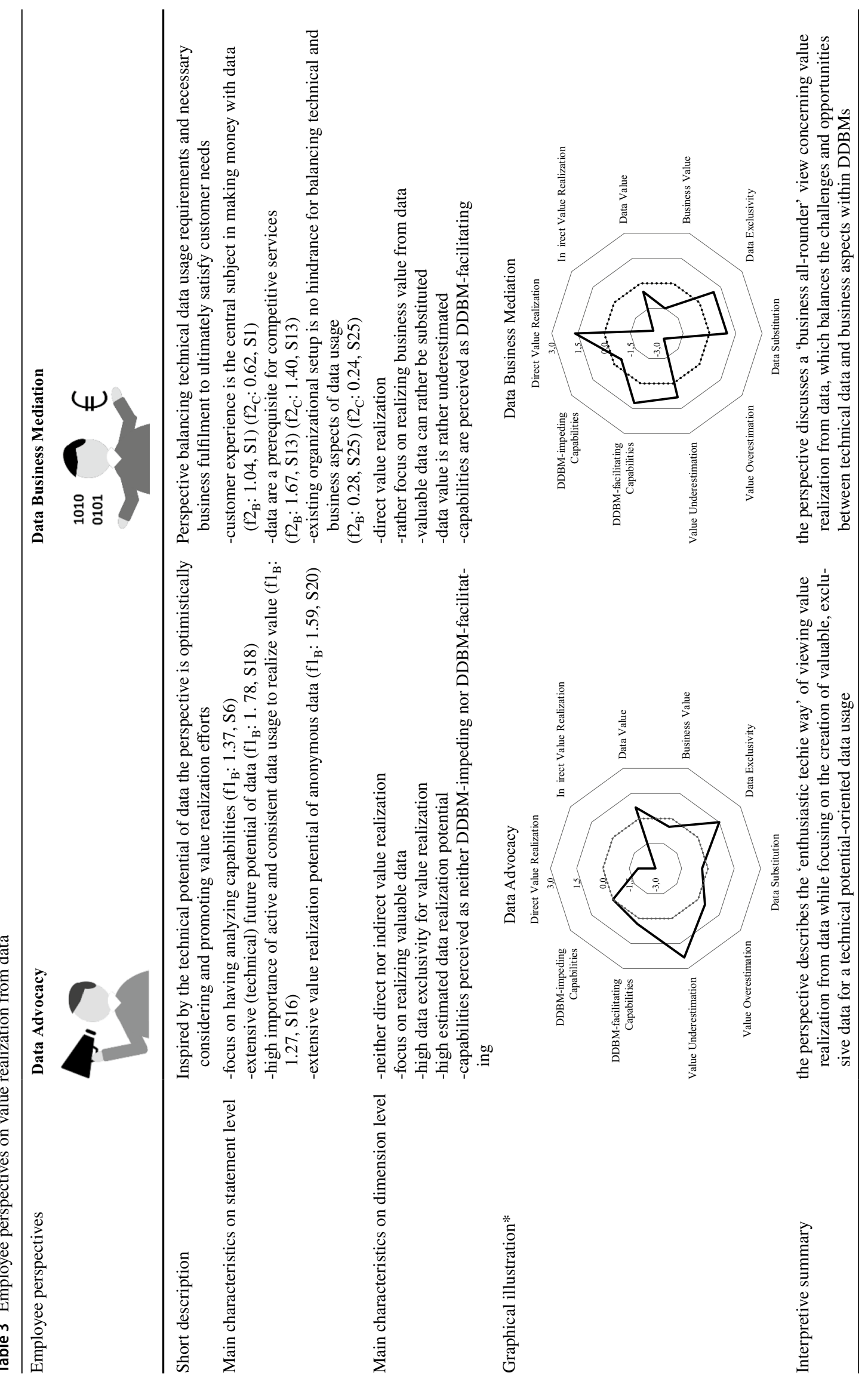




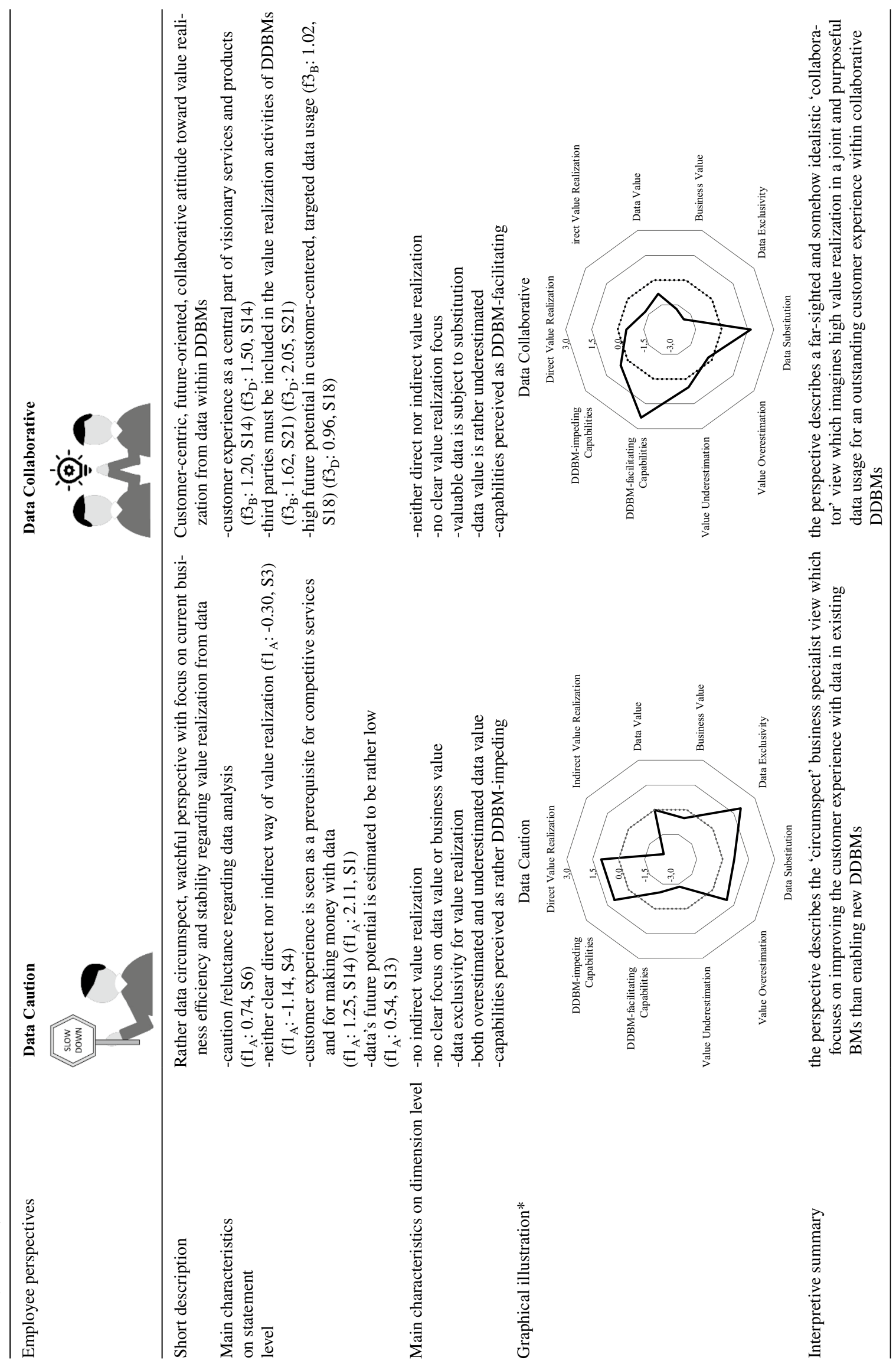




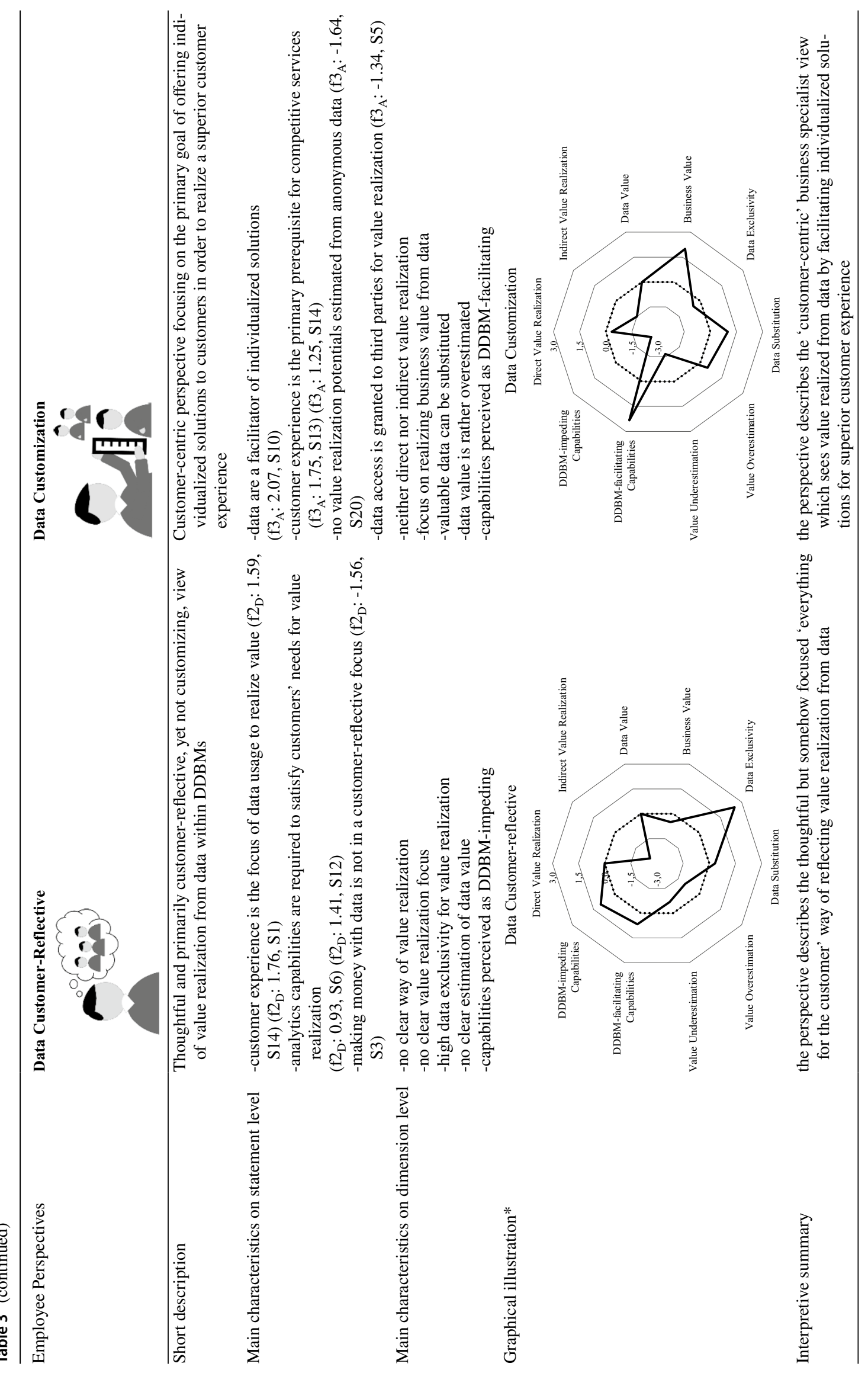




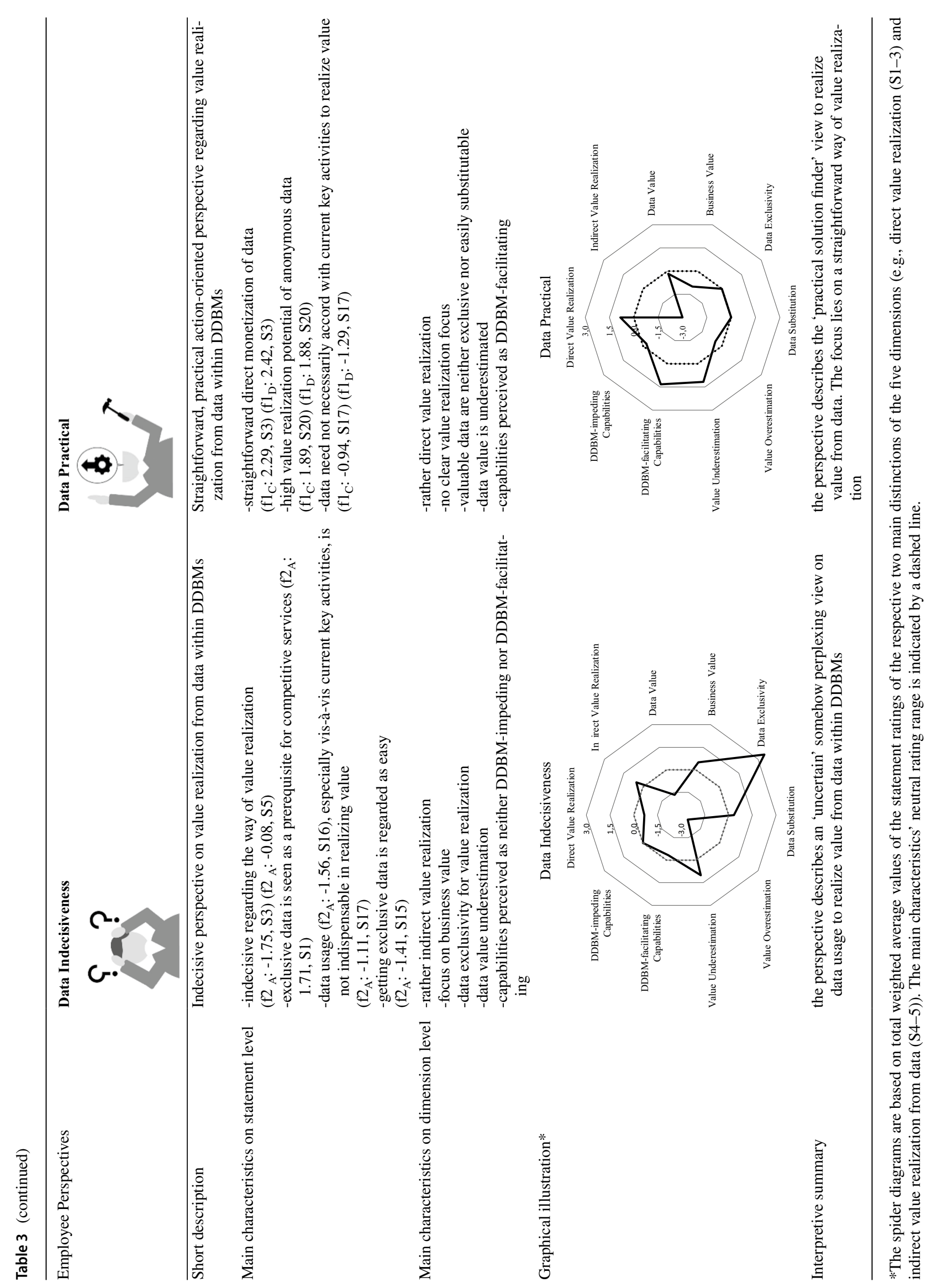




\section{Data business mediation perspective}

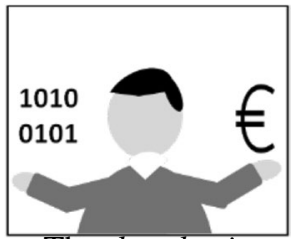

The data business mediation perspective describes a balancing view between the technical data usage requirements and the necessary business fulfillment to ultimately satisfy customer needs. Purposeful data usage while mediating between the technical data requirements and the business aspects is this perspective's central idea. Within DDBM 16-18, business potential is achieved via licensed data provision to third parties ( $\mathrm{f} 2_{\mathrm{B}}: 1.81, \mathrm{~S} 3$ ) ( $\mathrm{f} 2_{\mathrm{C}}: 2.08, \mathrm{~S} 3$ ) and via the cooperative development of new, customer-oriented services and an improved customer experience (f $2_{\mathrm{B}}: 1.12, \mathrm{~S} 21$ ). Overall, customer experience is regarded by employees who adopt this perspective as a central subject to make money with data ( $\left.\mathrm{f} 2_{\mathrm{B}}: 1.04, \mathrm{~S} 1\right)\left(\mathrm{f} 2_{\mathrm{C}}: 0.62, \mathrm{~S} 1\right)$ and third party data access is actively desired ( $\mathrm{f} 2_{\mathrm{B}}:-2.30, \mathrm{~S} 5$ ) ( $\left.\mathrm{f} 2_{\mathrm{C}}:-0.64, \mathrm{~S} 5\right)$. Data are considered prerequisites for competitive services ( $\mathrm{f} 2_{\mathrm{B}}$ : 1.67, S13) (f2 ${ }_{C}: 1.40, \mathrm{~S} 13$ ) which don't need to be exclusive to ensure competitive services (f $2_{\mathrm{B}}: 0.46, \mathrm{~S} 11$ ) (f $2_{\mathrm{C}}: 0.44, \mathrm{~S} 11$ ) since data are more likely to be easily substituted by other firms. Therefore, creating valuable data e.g., through processing ( $\left.\mathrm{f}_{\mathrm{B}}:-0.37, \mathrm{~S} 8\right)\left(\mathrm{f} 2_{\mathrm{C}}:-0.19, \mathrm{~S} 8\right)$ or combining different data sets $\left(\mathrm{f} 2_{\mathrm{B}}: 0.04, \mathrm{~S} 12\right)\left(\mathrm{f} 2_{\mathrm{C}}: 0.76, \mathrm{~S} 12\right)$ is rather unimportant. Existing organizational setups are not a major hindrance to balancing the technical and business aspects of data usage ( $\mathrm{f} 2_{\mathrm{B}}$ : $0.28, \mathrm{~S} 25$ ) ( $\mathrm{f} 2_{\mathrm{C}}: 0.24, \mathrm{~S} 25$ ). Thus, the data business mediation perspective describes a 'business all-rounder' view that balances the challenges and opportunities of technical data issues and business elements. Employees who adopt this meditative perspective understand how to satisfy customer needs through the purposeful use of technically sophisticated data sets.

\section{Data caution perspective}

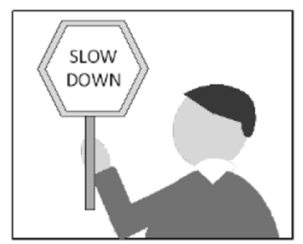

Data caution describes a rather data circumspect, watchful, current business efficiency- and stability-focused perspective regarding value realization from data. Based on knowledge about value realization in former BMs, employees who adopt this perspective appraise customer experience as a key prerequisite for competitive services ( $\left.\mathrm{f}_{\mathrm{A}}: 1.25, \mathrm{~S} 14\right)$ and for making money with data $\left(\mathrm{f} 1_{\mathrm{A}}: 2.11, \mathrm{~S} 1\right)$. However, due to their watchful focus on business efficiency and stability, these employees are rather cautious and reluctant concerning the use of data analytics to create value ( $\left.\mathrm{f}_{\mathrm{A}}: 0.74, \mathrm{~S} 6\right)$. Overall, the future potential for data is rather estimated low $\left(\mathrm{f} 1_{\mathrm{A}}: 0.54, \mathrm{~S} 13\right)$. The data caution perspective considers competitive services to be grounded on exclusive data $\left(\mathrm{fl}_{\mathrm{A}}\right.$ : $1.38, \mathrm{~S} 11)$ and, thus, does not consider third party collaborations to improve customers' experience ( $\mathrm{fl}_{\mathrm{A}}$ : $\left.-0.91, \mathrm{~S} 21\right)$. This perspective involves a certain tentativeness about using data e.g., anonymous data ( $\mathrm{f}_{\mathrm{A}}$ : $\left.-1.75, \mathrm{~S} 19\right)$ or commodity data from existing BMs $\left(\mathrm{fl}_{\mathrm{A}}\right.$ : $\left.-0.59, \mathrm{~S} 7\right)$ to improve business decisions in order to realize business value $\left(\mathrm{f} 1_{\mathrm{A}}:-1.25\right.$, $\mathrm{S} 14)$. Employees who adopt this perspective are rather cautious toward direct value realization from data e.g., via licensing $\left(\mathrm{fl}_{\mathrm{A}}:-0.30, \mathrm{~S} 3\right)$ or indirect value realization from data e.g., via cost reductions ( $\left.\mathrm{f}_{\mathrm{A}}:-1.14, \mathrm{~S} 4\right)$. Summarizing, the data caution perspective describes a rather circumspect business-specialist view that focuses on improving customers' experience with data in existing BMs, rather than enabling new DDBMs.

\section{Data collaborative perspective}

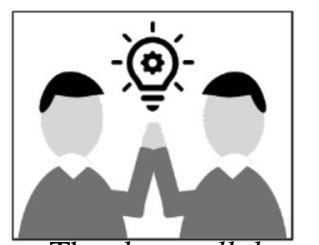

The data collaborative perspective describes a customercentric, future-oriented, collaborative employee attitude toward value realization from data. One of this perspective's two fundamental inner essences is that superior customer experience is essential within DDBMs - whether in terms of making money $\left(\mathrm{f} 3_{\mathrm{B}}: 1.07, \mathrm{~S} 1\right)\left(\mathrm{f} 3_{\mathrm{D}}: 0.60, \mathrm{~S} 1\right)$ or creating competitive services ( $\left.\mathrm{f}_{\mathrm{B}}: 1.20, \mathrm{~S} 14\right)\left(\mathrm{f} 3_{\mathrm{D}}: 1.50, \mathrm{~S} 14\right)$. The other inner essence is the importance for collaboration to achieve the necessary customer experience. Third parties must be included in value realization activities $\left(\mathrm{f} 3_{\mathrm{B}}: 1.62, \mathrm{~S} 21\right)\left(\mathrm{f} 3_{\mathrm{D}}\right.$ : $2.05, \mathrm{~S} 21)$, e.g., through the joint development or integration of third party services. This perspective aims not to create valuable data ( $\mathrm{f}_{\mathrm{B}}$ : $\left.-0.64, \mathrm{~S} 8\right)\left(\mathrm{f} 3_{\mathrm{D}}:-1.36, \mathrm{~S} 8\right)$ e.g., by combining data sets ( $\left.\mathrm{f}_{\mathrm{B}}:-1.41, \mathrm{~S} 12\right)\left(\mathrm{f} 3_{\mathrm{D}}:-1.23, \mathrm{~S} 12\right)$ and data are rather to treat as substitutable resources and only conditionally as prerequisites for competitive services ( $\left(3_{B}: 0.74, S 13\right.$ ) (f3 ${ }_{D}$ : $0.01, \mathrm{~S} 13)$. Significant future business potential is predominantly attributed to customer-centered data usage ( $\mathrm{f}_{\mathrm{B}}: 1.02$, $\mathrm{S} 18$ ) ( $\mathrm{f} 3_{\mathrm{D}}$ : $0.96, \mathrm{~S} 18$ ), yet a clear way of value realization is not intended (f3 $\mathrm{D}:-2.41, \mathrm{~S} 3)\left(\mathrm{f} 3_{\mathrm{B}}:-1.25, \mathrm{~S} 4\right)\left(\mathrm{f} 3_{\mathrm{B}}:-1.04\right.$, $\mathrm{S} 5)$. Since this visionary perspective is future-oriented, it considers the present, realizable value potential of data to be low $\left(\mathrm{f} 3_{\mathrm{B}}:-0.90, \mathrm{~S} 19\right)\left(\mathrm{f} 3_{\mathrm{D}}:-0.60, \mathrm{~S} 19\right)$. To ensure a collaborative value realization, this perspective calls for an IT agility $\left(\mathrm{f} 3_{\mathrm{B}}: 1.08, \mathrm{~S} 22\right)$ and a strategic anchoring ( $\left.\mathrm{f} 3_{\mathrm{B}}: 1.06, \mathrm{~S} 23\right)$. Summarizing, the data collaborative perspective describes a 
far-sighted, idealistic 'collaborator' view that imagines extensive future value realization through joint, purposeful data use for an outstanding customer experience within DDBMs that satisfies future customer needs.

\section{Data customer-reflective perspective}

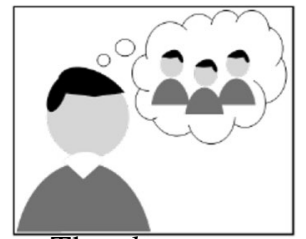

The data customer-reflective perspective describes a thoughtful and primarily customer-reflective-yet not customized - attitude toward value realization from data within DDBMs. From this perspective, the customer is at the core of all thoughts about value realization from data. Consequently, the customer experience is considered the key prerequisite for competitive services ( $\mathrm{f} 2_{\mathrm{D}}: 1.59, \mathrm{~S} 14$ ) and making money with data ( $\left.\mathrm{f}_{\mathrm{D}}: 1.76, \mathrm{~S} 1\right)$. This perspective's main idea is that data are the tool to satisfy customers' needs and data usage must entirely complement a superior customer experience. To use data in this respect, analytics capabilities are required ( $\left.2_{2}: 0.93, \mathrm{~S} 6\right)$ - especially to combine different data sets ( $\mathrm{f} 2 \mathrm{D}: 1.41, \mathrm{~S} 12)$ in order to reveal customer insights. Data do not need to pay in a firm's key activities to realize value $\left(2_{\mathrm{D}}:-1.15, \mathrm{~S} 17\right)$ and in line with the customer focus, data are not used to realize value directly e.g., via data licensing ( $f 2_{\mathrm{D}}$ : $-1.56, \mathrm{~S} 3$ ) or indirectly by reducing cost ( $\left(2_{\mathrm{D}}:-1.24, \mathrm{~S} 4\right)$ and preventing data access (f2 ${ }_{\mathrm{D}}:-1.35, \mathrm{~S} 5$ ). To react to changing customer needs, a certain degree of IT adaptability ( $\left.2_{2}: 0.53, \mathrm{~S} 10\right)$ and organizational flexibility (f $2_{\mathrm{D}}: 0.62, \mathrm{~S} 25$ ) is required. Overall, the data customer-reflective perspective describes a thoughtful but somehow focused 'everything for the customer' conception of reflecting value realization from data. Compared to the data customization perspective, the customer-reflective perspective focuses more on understanding a group of customers in order to satisfy their needs with the right solutions that are not necessarily individualized.

\section{Data customization perspective}

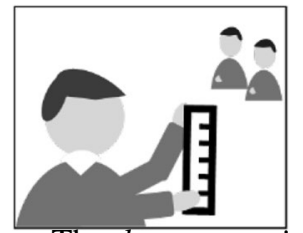

The data customization perspective describes a customercentric view of value realization from data within DDBMs, focusing on the primary goal of offering individualized solutions to customers in order to achieve a superior customer experience. This perspective focuses on offering individualized customer solutions to realize business value from data ( $\mathrm{f} 3_{\mathrm{A}}: 2.07, \mathrm{~S} 10$ ). Meanwhile, both data and customers' experience are regarded as important prerequisites for customization ( $\mathrm{f}_{\mathrm{A}}: 1.75, \mathrm{~S} 13$ ) ( $\left.\mathrm{f}_{\mathrm{A}}: 1.25, \mathrm{~S} 19\right)$. The perspective does not focus on creating valuable data e.g., by analyzing capabilities ( $\mathrm{f}_{\mathrm{A}}: 0.23, \mathrm{~S} 6$ ) or creating exclusive data by combing different data sets ( $\left.\mathrm{f}_{\mathrm{A}}:-0.01, \mathrm{~S} 12\right)$. In line with the customer-centricity and the efforts to offer individualized solutions, employees who adopt this perspective estimate the value of anonymous data to be low ( $\left.f 3_{\mathrm{A}}:-1.64, \mathrm{~S} 20\right)$. To improve the customers' experience, data access is granted to third parties ( $\mathrm{f} 3_{\mathrm{A}}:-1.34, \mathrm{~S} 5$ ) and employees with the data customization perspective are rather open to including third party services in the own service portfolios ( $\mathrm{f}_{\mathrm{A}}: 0.58$, $\mathrm{S} 21$ ). However, employees who adopt this perspective regard existing organizational setups as a constraining factor for individualized services ( $\mathrm{f} 3_{\mathrm{A}}:-1.64, \mathrm{~S} 25$ ), and they demand more IT adaptability ( $\left.\mathrm{f}_{\mathrm{A}}: 1.32, \mathrm{~S} 22\right)$ and strategic anchoring (f3 $\mathrm{A}_{\mathrm{A}}: 1.32, \mathrm{~S} 23$ ) for realizing customer-centricity. Essentially, the data customization perspective describes the customercentric business-specialist view which sees value from data realized by using them to facilitate individualized customer solutions for a superior customer experience. Thus, data are seen as a facilitator and a key prerequisite for customization.

\section{Data indecisiveness perspective}

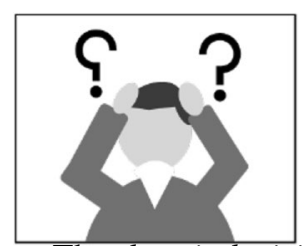

The data indecisiveness perspective describes an indecisive, somehow perplexing view on value realization from data within DDBMs. Data-especially exclusive data ( $\mathrm{f} 2 \mathrm{~A}$ : $1.71, \mathrm{~S} 11)$-are, to some extent sensed as a key prerequisite for competitive services according to this perspective ( $\mathrm{f} 2 \mathrm{~A}$ : $0.73, \mathrm{~S} 13)$, yet data usage ( $\left.2_{\mathrm{A}}:-1.56, \mathrm{~S} 16\right)$ - particularly data usage paying into the key activities of the firm (f $2_{\mathrm{A}}$ : - 1.11, S17)_are perceived as having minor importance. Employees who adopt this perspective regard exclusive data as easy to get ( $2_{\mathrm{A}}$ : $\left.-1.41, \mathrm{~S} 15\right)$ e.g., by combining different data sets ( $\left.2_{\mathrm{A}}: 1.61, \mathrm{~S} 12\right)$, yet they are indecisive as to whether their own analyzing and data processing capabilities are important to get exclusive data ( $\left.\mathrm{f}_{\mathrm{A}}: 0.29, \mathrm{~S} 6\right)$. Moreover, these employees are indecisive regarding the way of value realization ( $\mathrm{f} 2_{\mathrm{A}}:-1.75, \mathrm{~S} 3$ ) ( $\left.\mathrm{f} 2_{\mathrm{A}}:-0.08, \mathrm{~S} 5\right)$. Also, they harbor an ambiguous strategic orientation toward realizing valuable data e.g., through data processing or higher data volumes ( $\mathrm{f} 2 \mathrm{~A}:-1.53, \mathrm{~S} 8$ ) and toward realizing business value from data e.g., by using data to improve business decisions ( $\left.\mathrm{f} 2_{\mathrm{A}}:-0.56, \mathrm{~S} 9\right)$. Although, there is a need for getting exclusive data to be competitive ( $\left.2_{\mathrm{A}}: 1.71, \mathrm{~S} 11\right)$ the overall 
present and future business potential of data is rather estimated low (f2 $\left.{ }_{\mathrm{A}}: 0.43, \mathrm{~S} 18\right)\left(\mathrm{f} 2_{\mathrm{A}}:-0.53, \mathrm{~S} 19\right)$. Summarizing, the data indecisiveness perspective describes an 'uncertain' somehow perplexing view of data usage to realize value.

\section{Data practical perspective}

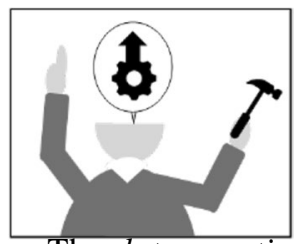

The data practical perspective describes a straightforward, pragmatically action-oriented approach to realizing value from data within DDBMs. This perspective reflects a strong opinion favoring direct value realization from data via licensing $\left(\mathrm{fl}_{\mathrm{C}}: 2.29, \mathrm{~S} 3\right)$. Indirect value realization from data e.g., by reducing costs $\left(\mathrm{fl}_{\mathrm{C}}:-1.69, \mathrm{~S} 4\right)$ or preventing third party data access is not a focus of this perspective ( $\mathrm{f} 1_{\mathrm{C}}$ : - 1.49, S5). DDBM19, a weather data service, in which this perspective occurs almost exclusively, helps to understand these characteristics. Since weather data is not an exclusive resource of only one firm, it is not necessary to keep this data highly exclusive and prevent them from access of third parties. Therefore, according to the rather pragmatic data practical perspective, such data can be used for direct value realization e.g., by licensing it. Moreover, this perspective does not aim to develop in-house analyzing capabilities in order to realize valuable data $\left(\mathrm{f}_{\mathrm{C}}:-1.32, \mathrm{~S} 6\right)$. Although the data practical perspective pursues a straightforward realization of business value from data e.g., by licensing data, it does not regard customers' experience as a central element of making money $\left(\mathrm{f} 1_{\mathrm{C}}:-1.08, \mathrm{~S} 1\right)$, and it does not believe data value depends on realizing highly individualized solutions ( $\left.\mathrm{f} 1_{C}:-0.78, \mathrm{~S} 10\right)\left(\mathrm{f}_{\mathrm{D}}:-0.84, \mathrm{~S} 210\right)$. Thus, even anonymous data-which do not reveal information about individual customers-have value ( $\mathrm{f} 1_{\mathrm{C}}: 1.89, \mathrm{~S} 20$ ) $\left(\mathrm{f} 1_{\mathrm{D}}: 1.88, \mathrm{~S} 20\right)$. This pragmatic view considers data to be a substitutable resource $\left(\mathrm{f} 1_{\mathrm{D}}:-1.10, \mathrm{~S} 11\right)$. Value is not realized by having exclusive data but, rather, by using exclusive data (f1 $\left.{ }_{C}: 0.53, \mathrm{~S} 16\right)\left(\mathrm{f} 1_{\mathrm{D}}: 0.69, \mathrm{~S} 16\right)$ - even if data usage is not part of a firm's key activities $\left(\mathrm{f} 1_{\mathrm{C}}:-0.94, \mathrm{~S} 17\right)\left(\mathrm{f} 1_{\mathrm{D}}\right.$ : -1.29 , S17) e.g., through licensing. Therefore, data's realizable value is more underestimated than overestimated. For this action-oriented view, strategic anchoring is required in order to ensure the capabilities' necessary agility ( $\mathrm{f}_{\mathrm{C}}: 1.22$, S23), and the existing organizational setups may be disadvantageous ( $\left.f 1_{C}: 1.40, \mathrm{~S} 25\right)$ for straightforward data value realization approaches. Thus, the data practical perspective describes the 'practical solution finder' view to realizing value from data.

\section{Discussion and conclusion}

Firms innovate DDBMs to realize value from data (Hilbig et al., 2020), but they often fall short of expected value realization (Court, 2015). We believe that one reason why DDBMs have yet not ignited in terms of value realization is that firms do not pay enough attention to the perspectives of their employees, a key stakeholder group with close integration in a firm and active engagement within DDBMs (Freudenreich et al., 2019). Thus, firms simply do not know how their employees view this complex and multi-faceted topic. Using the stakeholder theory (Freeman, 1984), we addressed this research gap with a QM execution in accordance with Stephenson (1936, 1953) and unveiled different perspectives on value realization from data. It was crucial for our research to identify what these perspectives and their thematic main characteristics are. Our research also sought to identify where they show differences and similarities. The aim of this was to better understand what aspects employees pay special attention to when they take actions to realize value from data within DDBMs.

This section delineates the study's contribution to research by discussing the explored eight employee perspectives along their five dimensions in terms of content. Regarding value realization from data, we further discuss the perspectives' main characteristics, particularly those that employees are especially interested in. Additionally, the findings' contributions are accentuated as new knowledge for research. Following, this section presents the practical implications of our findings, outlines the limitations of our investigation, and states both our recommendations for further research and our final and concluding thoughts.

\section{Contribution to research}

Our empirical investigation on employee perspectives on value realization from data within DDBMs reveals eight perspectives among 70 employees of a German car manufacturer. These perspectives include the following: the circumspect data caution perspective; the perplexed data indecisiveness perspective; the data practical solution-finder perspective; the data business mediation perspective; the data customization and data customer-reflective perspectives, which place strong focus on customers in realizing value; and the data advocacy and data collaborative perspectives, which consider high value potential for data and actively promote (collaborative) value realization efforts. As the hypernyms indicate, these eight perspectives show significant differences in both the overall characteristics across the five dimensions and in the single aspect in terms of content (see perspective overview in Table 3 ).

The differences in the perspectives support the idea that employees represent a stakeholder group that is not only 
powerful but very diverse (Wolfe \& Putler, 2002), holding different reciprocal and complementary opinions, interests and priorities (Freeman, 1984; Jones, 1995), according to which they judge matters like value realization from data. These differences can be a critical mechanism underlying innovation (Kelley \& Littman, 2005), as they mutually expand the employee's own perspective (Bittner \& Leimeister, 2014) and provide a basis upon which to challenge possible onesided DDBM ideas for value realization. For example, in DDBM 2, the data customer-reflective and data collaborative perspectives mutually expanded their respective viewpoints during DDBM innovation, which can be assumed as a benefit. DDBM 2-where a third party with expertise in digital assistance technology and a complementary infotainment ecosystem made a central contribution to the DDBMwas initially viewed rather critically by employees with the customer-reflective perspective. The employees assumed that sensitive automotive service-related customer data could possibly emigrate as a result of the collaboration; in this way, the third party would be able to build up a supplementary automotive service ecosystem. Employees with the data collaborative perspective emphasized the importance of the third party technology for the success of the DDBM and the long-term customer retention resulting from an outstanding customer experience. Through the exchange and mutual expansion of viewpoints, the implementation of the third party technology was ultimately designed with a clear separation of the ecosystems; this preserved customer knowledge for the further development of automotive services within the firm. Thus, the DDBM did not threaten the primal automotive service business, and the firm was still able to satisfy the 'automotive customer'. Moreover, this example shows that the perspectives' heterogeneity ensures a comprehensive consideration of all relevant aspects of value realization within DDBMs e.g., customer experience (Ugray et al., 2019) or a technological sophistication e.g., in data analytics (Harris, 2012). Yet, on the other hand, the perspectives' heterogeneity could lead to disharmony and divergence within DDBMs (Miller et al., 2014). For example, the data caution and data advocacy perspectives differ considerably in their main characteristics; this may lead to divergent prioritizations and allocations of limited resources, and it may even lead to conflicts within DDBMs. These conflicts, in turn, could impair value realization. In combination, these two perspectives may offer the best possible compromise between protection and data usage.

For a better understanding of 'what employee perspectives are', it is important to examine the perspectives in terms of their main characteristics of differentiation. This is crucial, as 'value realization from data' is a complex, high-level topic with a broad variety of thematic aspects (Günther et al., 2017a; Günther et al., 2017a, 2017b) all of which concern employees to some extent. However, as the previous paragraph has shown, perspectives differ significantly, and employees may be particularly interested in certain aspects e.g., customer experience (Ugray et al., 2019), as a result of previous experiences, functional backgrounds, or operational activities. With regards to these respective aspects, employees pay special attention to when they act in order to realize value from data within DDBMs. The perspectives are therefore strongly characterized by these aspects, as expressed by the QM statement factor loadings. Along with the five thematic dimensions of the perspectives, each containing five statements as academic and/or practical viewpoints, the perspectives and their different main characteristics are discussed in the following.

\section{Way of value realization}

As expected, our findings in this dimension show clear differences among the perspectives. For instance, perspectives such as the data practical or data business mediation feature strong characteristics in terms of direct value realization, whereas the data indecisiveness perspective tends to favor indirect value realization e.g., through cost reduction. Several viable ways to realize value from data are seen, confirming the idea raised in the literature (Akred \& Samani, 2018; Wixom \& Ross, 2017). Interestingly, employees who adopt a data collaborative perspective-where value is particularly realized through the creation of customer-centric DDBM collaborations (one main characteristic)—do not follow a clear direction in this regard. Both directions are conceivable for data collaborative employees, as long as their DDBMs pursue customer-centric solutions. This finding highlights a central idea of the current literature, namely the importance of customer centricity to achieve a good customer experience in order to ultimately realize value within DDBMs (Ugray et al., 2019; Weill \& Woerner, 2015). A closer look at data privacy as a concrete issue-especially in the case of direct data monetization (Koutroumpis et al., 2020; Malgieri \& Custers, 2018)—notably reveals that, across all eight perspectives, employees do not perceive privacy to be at risk when data are directly monetized. The interviewees claimed they felt this way because the monetization of non-personal or even anonymized data affords DDBMs great value realization potential. Thus, economic reasoning suggests no need to directly monetize personalized data, which could threaten data privacy and, in turn, be detrimental to DDBMs. This finding is interesting but surprising, as firms often argue that the monetization of non-personal or anonymous data is not economically valuable. They also tend to argue that data privacy complicates monetization (Kugler, 2018), overrules it, or makes it impossible. The findings show that the perspectives of the employees who innovate and operate DDBMs diverge from this view.

\section{Focus of value realization}

Academics e.g., Akter and Wamba (2016) or Grover et al. (2018) and practitioners have identified two main foci 
shaping this dimension: a focus on generating 'valuable data' and a focus on generating 'business value' by using data, including data that are considered to be of no apparent value in the first place. This became a dimension which decisively shaped the perspectives due to the slew of ramifications for a DDBM e.g., activities and aspects related to collecting, processing, and generating 'neat' data for value realization (Baldassarre et al., 2018; Exner et al., 2017; Hartmann et al., 2016). Interestingly, we unveiled some expected but also somewhat surprising findings in this regard. For instance, the hypothesis regarding the economic meaning of costly data turned out to be an interesting issue that ultimately shaped the perspectives. This hypothesis suggested that costly data (through considerable data processing) have a potentially higher value than 'cheap' data, or data that has not undergone work-intensive and time-consuming processing. As our findings show, there is no connection between more costly and more valuable data across the eight perspectives. Hence, minimal attention was paid to this issue. Employees who adopt the data customization perspective also deny this connection. This was only meaningful to these employees if costly data enabled more customized services, and this was not the case. This finding is interesting, as cost-intensive processing activities by data analytics are often justified with the assumption that more processed data could realize higher values in return (see also Ransbotham et al. (2016)). This point raises multiple questions e.g., whether this argument is misused to argue for resources or whether it is just a human misjudgement suggesting that something that costs more is worth more. Higher value realization through more data processing, however, was not assumed per se in this regard.

\section{Competitive data resources}

Across the perspectives and in regards to value realization, a more controversially-viewed issue is the question of scarce, firm-exclusive data as a crucial competitive differentiator (Beath et al., 2012; Hagiu \& Wright, 2020; Lambrecht \& Tucker, 2015) and the subsequent issue of third party inclusion and data access and whether value is realized by firm-exclusive data e.g., if data is not shared with other firms (Fruhwirth et al., 2019). Our findings show that employees who adopt a data customization perspective consider open relationships with third parties as important, favoring their inclusion in DDBMs' value realization activities. In accordance with literature, they also do not fear a loss of competitive advantage or less value realization by sharing data and collaborating with third parties (Duch-Brown et al., 2017; Kerber, 2019). Meanwhile, employees who adopt the data indecisiveness perspective strongly consider firm-exclusive data as a key factor for competitive services. To avoid the risk of easy data substitutability, they consider the internal combination of data sets from different sources to be of particular importance. This perspective characteristic is reasonable, as it is in line with the overall 'uncertain', somewhat perplexing view on data to realize value within DDBMs. In other words, if employees with the data indecisiveness perspective do not have a consistent idea of how to turn data into value, but the general ductus is that data is the most valuable firm resource (The Economist, 2017; Nolin, 2019), then there is a reasonable tendency to consider data as a resource to be kept as exclusive as possible. This view is shared with employees who adopt the data caution perspective. Based on these findings, it can be concluded that employees who are rather uncertain or circumspect about how to realize value from data are more averse to collaborative actions with third parties; this underestimates the value of third party expertise in helping to improve the customer experience, and it leads to measures that keep data firm-exclusive for precautionary reasons. Derived from the characteristics of these perspectives, one can better comprehend employee motivation to maintain the current business stability of the firm by keeping data firm-exclusive within DDBMs.

\section{Data value estimation}

As outlined above, there are very positive opinions attributing data enormous value potentials (Nolin, 2019). On the other hand, there are also rather reserved estimations (Ross et al., 2013). The unveiled perspectives confirm this differentiated picture. For instance, with the somewhat visionary, data-enthusiastic data advocacy and data collaborative perspectives, there are some optimistic estimations regarding the realizable value potentials. On the contrary, there are also more reserved estimations e.g., by employees with the data caution or the data practical perspectives. The data practical perspective, for example, considers data as having an inherent value in the present and a 'moderate' higher value potential in future DDBMs. However, according to employees with the data practical perspective the question of realizing the highest possible value is of a more conceptual nature. A moderate but appropriate value is to be pursued by more straightforward actions e.g., through licensing in DDBMs. A closer look at the differences in the individual perspective characteristics also brings interesting findings to light. For example, employees with the data practical perspective attribute a high value potential to anonymous data, even higher than those with the data advocacy perspective. This must be seen from the viewpoint that anonymized data currently plays a major role in the automotive service market (e.g., see Otonomo (2019)). Interesting characteristics in this dimension are found within the data business mediation perspective, which shows features like the 'T-shaped expert', according to Schymanietz and Jonas (2020). These are experts at linking insights from the technical domain (e.g., the technical-functional scope of data analysis tools) to the business domain and expressing how the technical domain can be used to address customer needs or affect differentiation from competitors, leading to realizing economic value through data analysis. These perspective characteristics of being able to understand, balance and link technical and business-related aspects within DDBMs 
shapes the balanced and differentiated view regarding this dimension. Like employees with the data advocacy perspective, employees with data business mediation perspectives attribute a currently still underestimated value potential to data in future DDBMs. However, to realize the value potentials the technical domain must enable a targeted data usage for business purposes. Also, both perspectives consider the previously expected value from data within DDBMs as quite accurately realized. This highlights the ability of these perspectives to give important input in establishing methods and tools to determine the realizable value from data (see Engels (2019); Soley et al. (2018)). Despite some methodical approaches, this remains as a challenging task.

\section{Competitive DDBM capabilities}

In the previous dimensions, we reflected particularly on the differences between the eight perspectives. The perspective characteristics of this dimension shows many similarities. For instance, all eight perspectives see an adaptable IT infrastructure as able to process and manage data to cope with growing or changing business- or technical-related demands as important or at least to be considered for realizing value in the long run (Vanauer et al., 2015). There is also consensus among the perspectives that value realization requires a corresponding strategic anchoring, for example in the form of a data analytics strategy (Ransbotham et al., 2016) grounding on internal and external demands or information security concerns (Ghoshal et al., 2014). The data caution perspective is the only perspective that does not attribute much importance to a strategic anchoring to realize value. This can be explained by the fact that the perspective is circumspect and watchful with regards to changes that may have an impact on the current business efficiency and stability. A strategic anchoring e.g., in the form of a data analytics strategy creates changes within a DDBM (resource-related, procedural or structural changes according to strategic policies). These changes could have an impact on the current business stability of DDBMs, especially in a medium-term implementation period. Several academic papers have looked at the impacts of data protection regulations - such as GDPR on DDBMs (see BöhmeckeSchwafert and Niebel (2018); Köster (2021); Ziegler et al. (2019)) - and they have examined whether the regulatory obligations can be impeding for innovating DDBMs and realizing value. Across the perspectives, regulatory aspects were not considered as impediments for value realization. Only the data indecisiveness and data user-reflective perspectives tend to agree that the regulatory obligation to obtain customers' approval to use personal data constrains quick changes in value realization. The viewpoint of employees with the data indecisiveness perspective can be explained by the fact that it is a generally uncertain and somewhat perplexing view on data usage, categorizing the obtaining of approvals as a constraint. Employees with the data user-reflective perspective base their partial agreement with this statement on their focused reflection of value realization according to the "everything for the customer' viewpoint. For these employees, compliance with the policies to process personal customer data has a very important priority. This makes it an important counterbalance perspective to data practicals.

\section{Implications for practice}

Our findings on employee perspectives offer important implications for firms currently pursuing the challenge of innovating DDBMs to realize value from data. There are two particularly noteworthy practical implications in this study. First, the perspectives provide firms detailed answers regarding how their employees view value realization from data within DDBMs. This reveals why they consider certain issues of value realization particularly important. It also explains why they do not acknowledge other aspects as being of great importance, and consequently do not take them into further consideration. Knowing these different perspective characteristics helps firms to develop a differentiated understanding of their seemingly homogenous stakeholder group of employees, which is important to better comprehend the attitudes underlying the daily employee actions and interactions. Firms can use our findings as a first step to develop an understanding regarding differences, similarities, and synergies of their employees' perspectives, which may put them in a future position to ensure that DDBMs comprehensively consider all relevant aspects of value realization. Moreover, a greater sensitivity toward different employee perspectives adds to help practice to reduce potential conflicts regarding value realization from data between departments. It may also add to help preventing internal discrepancies between employees within one DDBM.

Second, knowledge about different perspectives serves as an exciting form of initial input, helping firms to potentially identify which employees are equipped to fulfil certain roles for DDBM innovation. For example, firms could place a level of emphasis on employees who adopt a data practical perspective if a rapid DDBM implementation is needed (e.g., to secure market shares). Hence, DDBMs may be designed to be a little less sophisticated for faster implementation. Furthermore, employee perspectives could be examined in the spotlight of possible employee roles. Practice could consider employees who adopt the data caution perspective as constructive challengers of DDBMs. Their thoughtful nature and ability to critically reflect on changes could lead to sustainable DDBM integration in a firm. A third exemplary indication is worth mentioning to demonstrate the practical implications of the findings in helping to build a basis for establishing compatible roles in the future. In our opinion, the characteristics of the data business mediation perspectivebalancing the technical domain to the business domain and 
expressing how the technical-functional scope can be used e.g., to address customer needs-would enable employees to serve in inter-departmental interface positions, especially in technically sophisticated DDBMs. Their ability to balance and link issues from the technical and business domain may also qualify them as DDBM leads. Although the design, deployment, and combination of certain employee roles was not an intended focus of the investigation, the findings provide initial indications for practice for identifying possible roles to deal with employees during DDBM innovation. If these findings are further developed, we are confident that they have the potential to positively influence DDBM challenges in succeeding and realizing value from data.

\section{Limitations, further research and conclusion}

\section{Limitations}

This study constitutes an empirically and conceptually sound groundwork on employee perspectives toward value realization from data within DDBMs, yet it is subject to certain limitations. One limitation is that the $q$-sort exercises are inherently based on subjective judgments (Stephenson, 1936, 1953). To overcome this limitation and achieve necessary objectivity and rigor, we sampled 20 pre-test $q$-sort exercises and $70 q$-sort exercises from 19 different DDBMs. Comparing Stainton Rogers (1995) suggested guideline of 40-50 q-sort exercises to reach rigor, our $90 q$-sort exercises promise remarkable rigor. Another limitation is the empirical setting - mainly an automotive manufacturer. Accordingly, the findings' generalizability is restricted. However, to prevent the investigation from having a monolith-like character for overrepresenting the automotive industry, we conducted $13 q$-sort exercises and eleven post- $q$ sort interviews involving four other industries. Furthermore, we argue that alongside the automotive industry, at least similar perspectives - such as data caution, data practical, or data advocacy — can be found among employees in other manufacturing industries that are currently transforming their businesses and intensifying DDBM innovation, such as industrial mechanical engineering with its remote diagnostics and maintenance services (Weinberger et al., 2016) or aerospace engineering with its 'power-by-the-hour' DDBMs (Smith, 2013). Another limitation is that it focuses exclusively on employees, and it does not fully cover other stakeholder groups, such as suppliers or customers (Parmar et al., 2010).

\section{Further research}

In appraising the eight perspectives as an initial thematical inquiry into the employees' views on value realization from data within DDBMs, we recommend the following avenues for further research. First, complement the unveiled employee perspectives by examining other stakeholder perspectives - especially among customers, whose experience is a crucial element of value realization (Ugray et al., 2019). Second, include further industries that are transitioning from former, more physical BMs to DDBMs, and compare them with DDBM 'champions' from the digital-born tech sector. Third, examine whether certain past experiences, contextspecific interpretations, or belief systems decisively influence the perspectives (Tikkanen et al., 2005). Fourth, investigate whether there is an interplay between the perspectives and the DDBMs' overall designs. For example, whether in DDBMs that are largely extensions of existing BMs, rather circumspect or uncertain views are represented. Or if technical inspiration and adopting data-analytics as central DDBM capabilities to realize value from data play a decisive role in shaping far-sighted and data optimistic perspectives such as data advocacy, data collaborative or data customerreflective. Fifth, investigate how perspectives shape operational actions and interactions or influence organizational outcomes. This suggested research focus complements the managerial and instrumental aspects of the stakeholder theory (Jones, 1995), explaining how to effectively manage stakeholders with different perspectives in order to realize value from data within DDBMs.

\section{Conclusion}

We provided an initial empirical inquiry to understand value realization from data within DDBMs from the perspective of employees who are tightly involved in value realization. In this regard, we used the QM, according to Stephenson (1936, 1953 ) to examine employees' perspectives on this topic. This QM application provided the following eight perspectives: data advocacy, data business mediation, data caution, data collaborative, data customization, data customer-reflective, data indecisiveness and data practical. Moreover, we revealed detailed and comprehensive descriptions of these perspectives to enable a solid initial understanding e.g., through their main characteristics, and similarities and differences along their thematical dimensions. Thus, providing a first groundwork on how employees appraise value realization from data as a heterogeneous key stakeholder group that significantly influences the firms' value realization (Mitchell et al., 1997; Wolfe \& Putler, 2002). Moreover, especially in the context of innovating DDBMs, we addressed the current research on DDBMs and stakeholder management (Fruhwirth et al., 2018; Wiener et al., 2020), thus helping firms with their ongoing efforts to make DDBMs work and perfect value realization from data. The authors hope practitioners and researchers alike will find our research a valuable resource for making DDBMs work and, ultimately, realizing value from data. 


\section{Appendix A}

\section{Interviews}

\section{Guiding questions of the open interviews within the QM development phase:}

1. What is the value realization from data all about? What aspects does value realization from data take into account in the context of the data-driven business model (...)?

2. Which topics concern you at your daily work within the data-driven business model (...) with regard to the value realization from data, and why?

3. Which topics are of particular interest to you in the context of the data-driven business model (...) with regards to realizing value from data? What is particularly important, and why?

\section{Interviewees within the QM development phase}

\begin{tabular}{|c|c|c|c|c|c|}
\hline Interviewee profession & Functional category & Factor loadings & Interview types & DDBM & DDBM Name \\
\hline Data strategist & Strategy & - & open & DDBM1-3 & $\begin{array}{l}\text { Data-driven driving assistant, third party } \\
\text { data-driven driving assistant, data service } \\
\text { platform }\end{array}$ \\
\hline Digital strategist & Strategy & - & open & DDBM1\&2 & $\begin{array}{l}\text { Data-driven driving assistant, third party } \\
\text { data-driven driving assistant }\end{array}$ \\
\hline Digital service manager & DDBM lead & - & open & DDBM1\&2 & $\begin{array}{l}\text { Data-driven driving assistant, third party } \\
\text { data driven driving assistant }\end{array}$ \\
\hline Business manager & DDBM lead & - & open & DDBM1-3 & $\begin{array}{l}\text { Data driven driving assistant, data-driven } \\
\text { third party driving assistant, data service } \\
\text { platform }\end{array}$ \\
\hline Data analyst & IT & - & open & DDBM1\&2 & $\begin{array}{l}\text { Data driven driving assistant, third party } \\
\text { data-driven driving assistant }\end{array}$ \\
\hline Data analyst & IT & - & open & DDBM1 & Data-driven driving assistant \\
\hline Data protection specialist & IT & - & open & DDBM1-3 & $\begin{array}{l}\text { Data-driven driving assistant, third party } \\
\text { data-driven driving assistant, data service } \\
\text { platform }\end{array}$ \\
\hline Business analyst & Business & - & open & DDBM1-3 & $\begin{array}{l}\text { Data-driven driving assistant, third party } \\
\text { data-driven driving assistant, data service } \\
\text { platform }\end{array}$ \\
\hline Business controller & Business & - & open & DDBM1\&2 & $\begin{array}{l}\text { Data-driven driving assistant, third party } \\
\text { data-driven driving assistant }\end{array}$ \\
\hline $\begin{array}{l}\text { Digital purchasing } \\
\text { manager }\end{array}$ & Business & - & open & DDBM1\&2 & $\begin{array}{l}\text { Driving assistant, third party driving } \\
\text { assistant }\end{array}$ \\
\hline Partnering manager & Business & - & open & DDBM1\&2 & $\begin{array}{l}\text { Driving assistant, third party driving } \\
\text { assistant }\end{array}$ \\
\hline
\end{tabular}




\section{Guiding questions of the post q-sort interviews within the QM execution phase:}

1. You have sorted the statement $(*)$ to the positioning $(* *)$. Why did you sort it this way? What were your thoughts behind the sorting?

2. How does the sorting of this statement relate to the statements in the adjacent vertical scoring rows? How did you differentiate these statements from each other? Why did you sort them in this way?
3. In summary, looking at the sorting of the 25 statements, how would you describe your perspective on value realization from data within the data-driven business model $(\ldots)$ ?

Note. * This question is asked individually for all 25 q-sort statements.

** Individual statement sorting in the q-sort triangle (the sorting values rank from -4 (totally disagree) to +4 (totally agree)). Please see the exemplary q-sort in appendix B.

\section{Interviewees within the QM refinement \& pre-test phase}

\begin{tabular}{|c|c|c|c|c|c|}
\hline Interviewee profession & Functional category & Factor loadings & Interview types & DDBM & DDBM Name \\
\hline Data strategist & Strategy & - & open & DDBM1-3 & $\begin{array}{l}\text { Data-driven driving assistant, third party } \\
\text { data-driven driving assistant, data service } \\
\text { platform }\end{array}$ \\
\hline Digital strategist & Strategy & - & open & DDBM1\&2 & $\begin{array}{l}\text { Data-driven driving assistant, third party } \\
\text { data-driven driving assistant }\end{array}$ \\
\hline Business manager & DDBM lead & - & open & DDBM1-3 & $\begin{array}{l}\text { Data-driven driving assistant, third party } \\
\text { data-driven driving assistant, data service } \\
\text { platform }\end{array}$ \\
\hline Business analyst & Business & - & open & DDBM1-3 & $\begin{array}{l}\text { Data-driven driving assistant, third party } \\
\text { data-driven driving assistant, data service } \\
\text { platform }\end{array}$ \\
\hline $\begin{array}{l}\text { Digital purchasing } \\
\text { manager }\end{array}$ & Business & - & open & DDBM1\&2 & $\begin{array}{l}\text { Data-driven driving assistant, third party } \\
\text { data-driven driving assistant }\end{array}$ \\
\hline Marketing specialist & Business & f1T & - & DDBM4 & Data-driven maintenance and repair service \\
\hline Service specialist & Business & f1T & - & DDBM4 & Data-driven maintenance and repair service \\
\hline Business analyst & Business & $\mathrm{f} 2 \mathrm{~T}$ & - & DDBM5 & Customized used car service platform \\
\hline Business manager & DDBM lead & f1T & post q-sort & DDBM5 & Customized used car service platform \\
\hline Data strategist & Strategy & f3T & post q-sort & DDBM6 & Platform for collaborative data products \\
\hline Business director & DDBM lead & $\mathrm{f} 2 \mathrm{~T}$ & post q-sort & DDBM7 & Data-driven retail platform \\
\hline Business specialist & Business & f3T & post q-sort & DDBM7 & Data-driven retail platform \\
\hline IT manager & IT & $\mathrm{f} 2 \mathrm{~T}$ & post q-sort & DDBM8 & Highly automized recruiting service \\
\hline $\begin{array}{l}\text { Digital business } \\
\text { director }\end{array}$ & Project Lead & $\mathrm{f} 2 \mathrm{~T}$ & post q-sort & DDBM8 & Highly automized recruiting service \\
\hline IT manager & IT & $\mathrm{f} 2 \mathrm{~T}$ & post q-sort & DDBM9 & Personalized online education service \\
\hline Business manager & DDBM lead & f1T & post q-sort & DDBM9 & Personalized online education service \\
\hline Controlling specialist & Business & false & post q-sort & DDBM10 & Analytics-driven individual training platform \\
\hline IT architect & IT & f1T & post q-sort & DDBM10 & Analytics-driven individual training platform \\
\hline Technology specialist & IT & $\mathrm{f} 3 \mathrm{~T}$ & - & DDBM10 & Analytics-driven individual training platform \\
\hline Head of research & DDBM lead & f3T & post q-sort & DDBM11 & Telecommunication data provision service \\
\hline Research strategist & Strategy & f3T & post q-sort & DDBM11 & Telecommunication data provision service \\
\hline Research associate & Business & false & post q-sort & DDBM11 & Telecommunication data provision service \\
\hline Research associate & Business & $\mathrm{f} 2 \mathrm{~T}$ & post q-sort & DDBM11 & Telecommunication data provision service \\
\hline
\end{tabular}


Interviewees within the QM execution phase

\begin{tabular}{|c|c|c|c|c|c|}
\hline Interviewee profession & Functional category & Factor loadings & Interview types & DDBM & DDBM Name \\
\hline After sales specialist & Business & false & post q-sort & DDBM12 & Personalized warranty service \\
\hline Service specialist & Business & false & post q-sort & DDBM12 & Personalized warranty service \\
\hline Marketing specialist & Business & f2A & post q-sort & DDBM12 & Personalized warranty service \\
\hline Business analyst & Business & f1A & - & DDBM12 & Personalized warranty service \\
\hline Business manager & DDBM lead & f1A & post q-sort & DDBM12 & Personalized warranty service \\
\hline After sales specialist & Business & f2A & post q-sort & DDBM13 & Data-driven maintenance and loyalty service \\
\hline After sales manager & DDBM lead & $\mathrm{f} 3 \mathrm{~A}$ & post q-sort & DDBM13 & Data-driven maintenance and loyalty service \\
\hline Business analyst & Business & $\mathrm{f} 3 \mathrm{~A}$ & post q-sort & DDBM13 & Data-driven maintenance and loyalty service \\
\hline Marketing specialist & Business & $\mathrm{f} 2 \mathrm{~A}$ & - & DDBM13 & Data-driven maintenance and loyalty service \\
\hline Service specialist & Business & $\mathrm{f} 3 \mathrm{~A}$ & - & DDBM13 & Data-driven maintenance and loyalty service \\
\hline Data analyst & IT & $\mathrm{f} 3 \mathrm{~A}$ & post q-sort & DDBM14 & App-based repair service \\
\hline Business manager & DDBM lead & $\mathrm{f} 2 \mathrm{~A}$ & post q-sort & DDBM14 & App-based repair service \\
\hline Business analyst & Business & f1A & - & DDBM14 & App-based repair service \\
\hline Marketing specialist & Business & f2A & - & DDBM14 & App-based repair service \\
\hline Service specialist & Business & f1A & - & DDBM14 & App-based repair service \\
\hline Data analyst & IT & f1A & post q-sort & DDBM15 & Data-driven repair service \\
\hline Business manager & DDBM lead & f1A & post q-sort & DDBM15 & Data-driven repair service \\
\hline Business specialist & Business & f1A & post q-sort & DDBM15 & Data-driven repair service \\
\hline Marketing specialist & Business & $\mathrm{f} 2 \mathrm{~A}$ & - & DDBM15 & Data-driven repair service \\
\hline Service specialist & Business & f1A & - & DDBM15 & Data-driven repair service \\
\hline Business manager & DDBM lead & f2B & post q-sort & DDBM16 & Analytics driven real-time map service \\
\hline Digital strategist & Strategy & f3B & post q-sort & DDBM16 & Analytics driven real-time map service \\
\hline Business manager & Business & $\mathrm{f} 2 \mathrm{~B}$ & post q-sort & DDBM16 & Analytics driven real-time map service \\
\hline IT specialist & IT & f1B & post q-sort & DDBM16 & Analytics driven real-time map service \\
\hline Data analyst & IT & f2B & post q-sort & DDBM16 & Analytics driven real-time map service \\
\hline Digital strategist & Strategy & $\mathrm{f} 3 \mathrm{~B}$ & post q-sort & DDBM17 & Collaborative analytics driven real-time map service \\
\hline Business specialist & Business & f2B & post q-sort & DDBM17 & Collaborative analytics driven real-time map service \\
\hline Business analyst & Business & f2B & post q-sort & DDBM17 & Collaborative analytics driven real-time map service \\
\hline Data specialist & IT & f1B & post q-sort & DDBM17 & Collaborative analytics driven real-time map service \\
\hline Business specialist & Business & $\mathrm{f} 3 \mathrm{~B}$ & post q-sort & DDBM17 & Collaborative analytics driven real-time map service \\
\hline IT specialist & IT & f1B & post q-sort & DDBM17 & Collaborative analytics driven real-time map service \\
\hline Business manager & DDBM lead & f1B & post q-sort & DDBM17 & Collaborative analytics driven real-time map service \\
\hline Business analyst & Business & f1B & post q-sort & DDBM18 & Analytics driven charging service \\
\hline Data analyst & IT & f3B & post q-sort & DDBM18 & Analytics driven charging service \\
\hline Business manager & Business & $\mathrm{f} 2 \mathrm{~B}$ & post q-sort & DDBM18 & Analytics driven charging service \\
\hline Business specialist & Business & f1B & - & DDBM18 & Analytics driven charging service \\
\hline Business manager & DDBM lead & f1B & post q-sort & DDBM18 & Analytics driven charging service \\
\hline Digital strategy manager & Strategy & f1B & post q-sort & DDBM18 & Analytics driven charging service \\
\hline Business manager & DDBM lead & $\mathrm{f} 2 \mathrm{C}$ & post q-sort & DDBM3 & Data service platform \\
\hline Business manager & Business & $\mathrm{f} 2 \mathrm{C}$ & post q-sort & DDBM3 & Data service platform \\
\hline Business analyst & Business & $\mathrm{f} 2 \mathrm{C}$ & post q-sort & DDBM3 & Data service platform \\
\hline Business analyst & Business & $\mathrm{f} 2 \mathrm{C}$ & post q-sort & DDBM3 & Data service platform \\
\hline Data strategist & Strategy & $\mathrm{f} 2 \mathrm{C}$ & - & DDBM3 & Data service platform \\
\hline IT specialist & IT & false & post q-sort & DDBM3 & Data service platform \\
\hline Business analyst & Business & f1C & post q-sort & DDBM19 & Environment data service \\
\hline Business manager & DDBM lead & $\mathrm{f} 1 \mathrm{C}$ & post q-sort & DDBM19 & Environment data service \\
\hline Data analyst & IT & $\mathrm{f} 1 \mathrm{C}$ & post q-sort & DDBM19 & Environment data service \\
\hline Business specialist & Business & $\mathrm{f} 1 \mathrm{C}$ & post q-sort & DDBM19 & Environment data service \\
\hline Business specialist & Business & $\mathrm{f} 1 \mathrm{C}$ & post q-sort & DDBM19 & Environment data service \\
\hline
\end{tabular}




\begin{tabular}{|c|c|c|c|c|c|}
\hline Interviewee profession & Functional category & Factor loadings & Interview types & DDBM & DDBM Name \\
\hline Business manager & Business & f1C & post q-sort & DDBM19 & Environment data service \\
\hline Digital strategy manager & Strategy & $\mathrm{f} 2 \mathrm{C}$ & post q-sort & DDBM19 & Environment data service \\
\hline Data strategist & Strategy & f1D & post q-sort & DDBM6 & Platform for collaborative data products \\
\hline Business manager & DDBM lead & f1D & post q-sort & DDBM6 & Platform for collaborative data products \\
\hline IT specialist & Business & f1D & - & DDBM6 & Platform for collaborative data products \\
\hline IT specialist & IT & f1D & post q-sort & DDBM6 & Platform for collaborative data products \\
\hline Data analyst & IT & f1D & post q-sort & DDBM6 & Platform for collaborative data products \\
\hline Business specialist & Business & f1D & post q-sort & DDBM6 & Platform for collaborative data products \\
\hline Business specialist & Business & f1D & post q-sort & DDBM6 & Platform for collaborative data products \\
\hline Business controller & Business & $\mathrm{f} 3 \mathrm{D}$ & post q-sort & DDBM1 & Data-driven driving assistant \\
\hline Business specialist & Business & $\mathrm{f} 2 \mathrm{D}$ & post q-sort & DDBM1 & Data-driven driving assistant \\
\hline Data strategist & Strategy & $\mathrm{f} 2 \mathrm{D}$ & post q-sort & DDBM1 & Data-driven driving assistant \\
\hline Business analyst & Business & $\mathrm{f} 2 \mathrm{D}$ & - & DDBM1 & Data-driven driving assistant \\
\hline Data Analyst & IT & $\mathrm{f} 2 \mathrm{D}$ & post q-sort & DDBM1 & Data-driven driving assistant \\
\hline Data manager & DDBM lead & f $2 \mathrm{D}$ & post q-sort & DDBM1 & Data-driven driving assistant \\
\hline Business analyst & DDBM lead & $\mathrm{f} 3 \mathrm{D}$ & post q-sort & DDBM2 & Third party data-driven driving assistant \\
\hline Data Analyst & IT & $\mathrm{f} 2 \mathrm{D}$ & post q-sort & DDBM2 & Third party data-driven driving assistant \\
\hline Data strategist & Strategy & $\mathrm{f} 2 \mathrm{D}$ & post q-sort & DDBM2 & Third party data-driven driving assistant \\
\hline Business manager & Business & $\mathrm{f} 3 \mathrm{D}$ & post q-sort & DDBM2 & Third party data-driven driving assistant \\
\hline Data manager & IT & f1D & post q-sort & DDBM2 & Third party data-driven driving assistant \\
\hline Business controller & Business & $\mathrm{f} 3 \mathrm{D}$ & post q-sort & DDBM2 & Third party data-driven driving assistant \\
\hline
\end{tabular}

\section{Appendix B}

\section{Exemplary q-sort}

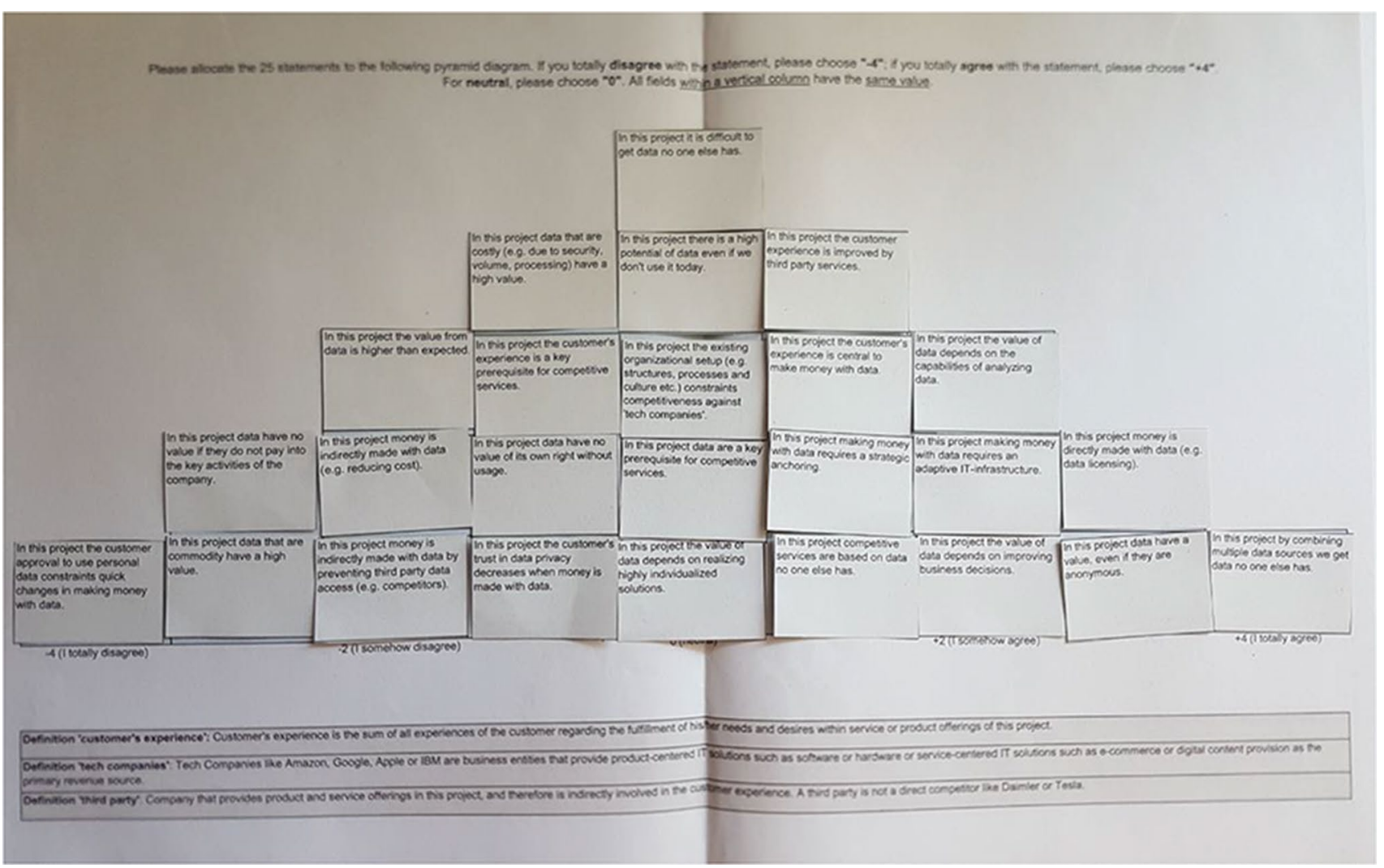




\section{Appendix C}

\section{Q-method factor characteristics and quality criteria}

\section{Premises for factor selection}

\begin{tabular}{ll}
\hline Criteria & Premises for factor selection \\
\hline Eigenvalues & Eigenvalues $>2.0$ \\
nload & nload $\geq 3$ (at least 3 DDBM actors load in one factor) \\
cum_expl_var & cum_expl_var $\geq 50.0$ (more than $50 \%$ of variance should be explained by the factors) \\
reliability & $\geq 90.0$ (composite reliability as internal consistency of the factor) \\
se_fscores & se_fscores $<0.25$ (standard error of the factors $<0.25)$ \\
factor loadings & balanced ratio of factor loadings between the factors \\
& $\geq(+-) 0.6$ [very strong loading] $\geq(+-) 0.4$ [strong loading], and $<(+-) 0.1$ [neutral loading] \\
z-scores & balanced ratio of factor loadings between the factors \\
& $\geq(+-) 2.0$ [very strong z-score], $\geq(+-) 1.0$ [strong z-score], and $<(+-) 0.1[$ neutral z-scores] \\
\hline
\end{tabular}

\section{Pre-test factor characteristics and quality criteria}

\begin{tabular}{lllllllllllll}
\hline & av_rel_coef & N load & eigenvals & expl_var & reliab & se_fscores & cor_zsc_f1 & cor_zsc_f2 & cor_zsc_f3 & sd_dif, f1 & sd_dif, f2 & sd_dif,f3 \\
\hline f1T & 0.8 & 5 & 3.6 & 19.8 & 0.95 & 0.22 & 1.00 & 0.37 & 0.10 & 0.31 & 0.30 & 0.31 \\
f2T & 0.8 & 6 & 3.4 & 18.9 & 0.96 & 0.20 & 0.37 & 1.00 & -0.07 & 0.30 & 0.28 & 0.30 \\
$\mathrm{f3T}$ & 0.8 & 5 & 2.4 & 13.6 & 0.95 & 0.22 & 0.10 & -0.07 & 1.00 & 0.31 & 0.30 & 0.31 \\
\hline
\end{tabular}

\section{Q-method factor characteristics and quality criteria}

\begin{tabular}{lllllllllllll}
\hline & av_rel_coef & N load & eigenvals & expl_var & reliab & se_fscores & cor_zsc_f1 & cor_zsc_f2 & cor_zsc_f3 & sd_dif, f1 & sd_dif,f2 & sd_dif,f3 \\
\hline f1A & 0.8 & 8 & 4.67 & 23.35 & 0.97 & 0.17 & 1.00 & 0.32 & 0.35 & 0.25 & 0.27 & 0.30 \\
f2A & 0.8 & 6 & 3.27 & 16.36 & 0.96 & 0.20 & 0.32 & 1.00 & 0.22 & 0.27 & 0.28 & 0.31 \\
f3A & 0.8 & 4 & 2.87 & 14.33 & 0.94 & 0.24 & 0.35 & 0.22 & 1.00 & 0.30 & 0.31 & 0.34 \\
f1B & 0.8 & 8 & 4.09 & 22.73 & 0.97 & 0.17 & 1.00 & 0.50 & 0.22 & 0.25 & 0.27 & 0.30 \\
f2B & 0.8 & 6 & 3.83 & 21.28 & 0.96 & 0.20 & 0.50 & 1.00 & 0.42 & 0.27 & 0.28 & 0.31 \\
f3B & 0.8 & 4 & 3.03 & 16.82 & 0.94 & 0.24 & 0.22 & 0.42 & 1.00 & 0.30 & 0.31 & 0.34 \\
f1C & 0.8 & 6 & 3.51 & 26.97 & 0.96 & 0.20 & 1.00 & 0.32 & - & 0.28 & 0.28 & - \\
f2C & 0.8 & 6 & 3.01 & 23.19 & 0.96 & 0.20 & 0.32 & 1.00 & - & 0.28 & 0.28 & - \\
f1D & 0.8 & 8 & 4.24 & 22.31 & 0.97 & 0.17 & 1.00 & 0.08 & 0.01 & 0.25 & 0.25 & 0.30 \\
f2D & 0.8 & 7 & 4.01 & 21.56 & 0.97 & 0.19 & 0.08 & 1.00 & 0.34 & 0.25 & 0.26 & 0.31 \\
f3D & 0.8 & 4 & 2.41 & 12.69 & 0.94 & 0.24 & 0.01 & 0.34 & 1.00 & 0.30 & 0.31 & 0.34 \\
\hline
\end{tabular}


798

M. Förster et al.

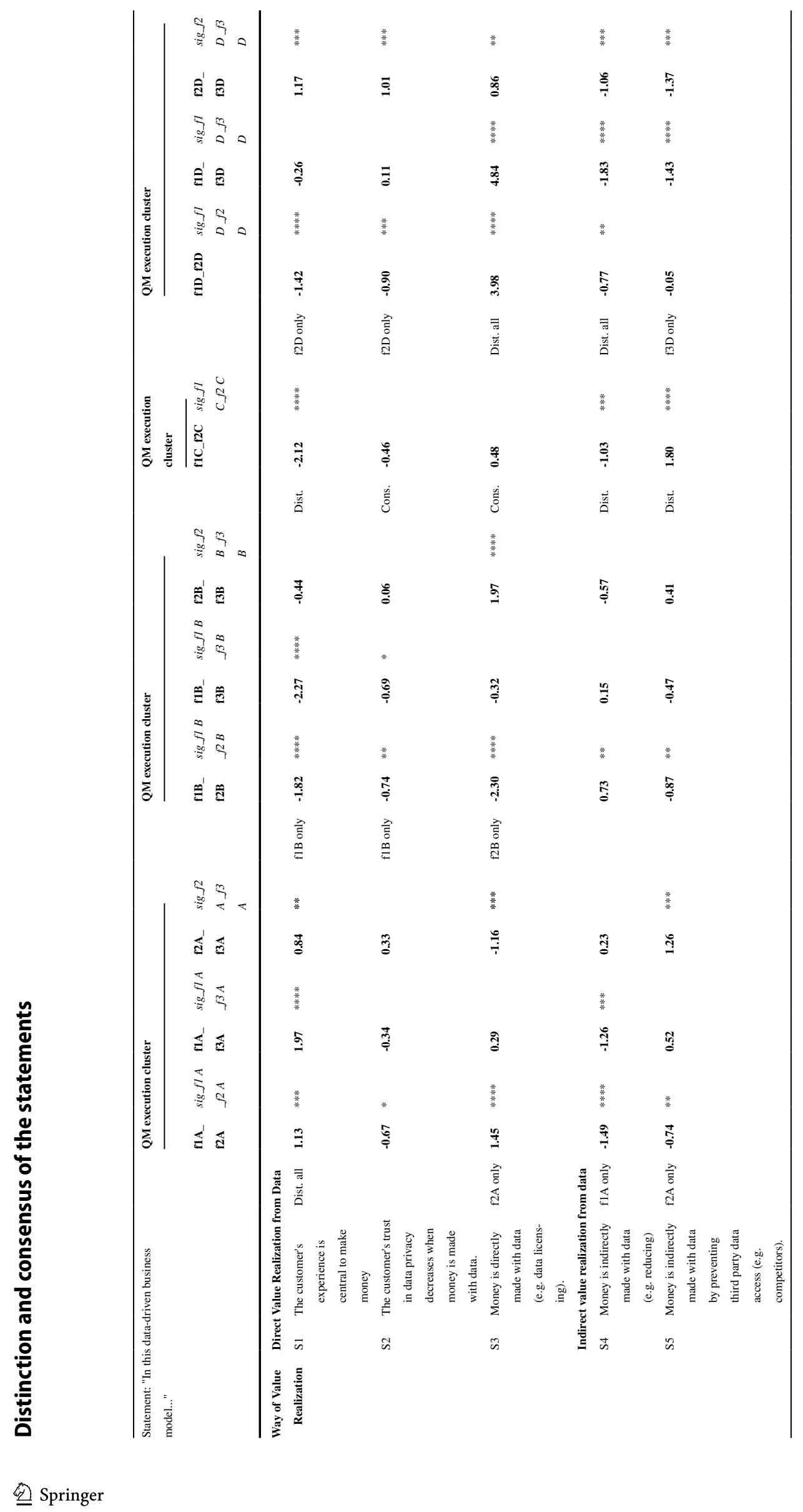




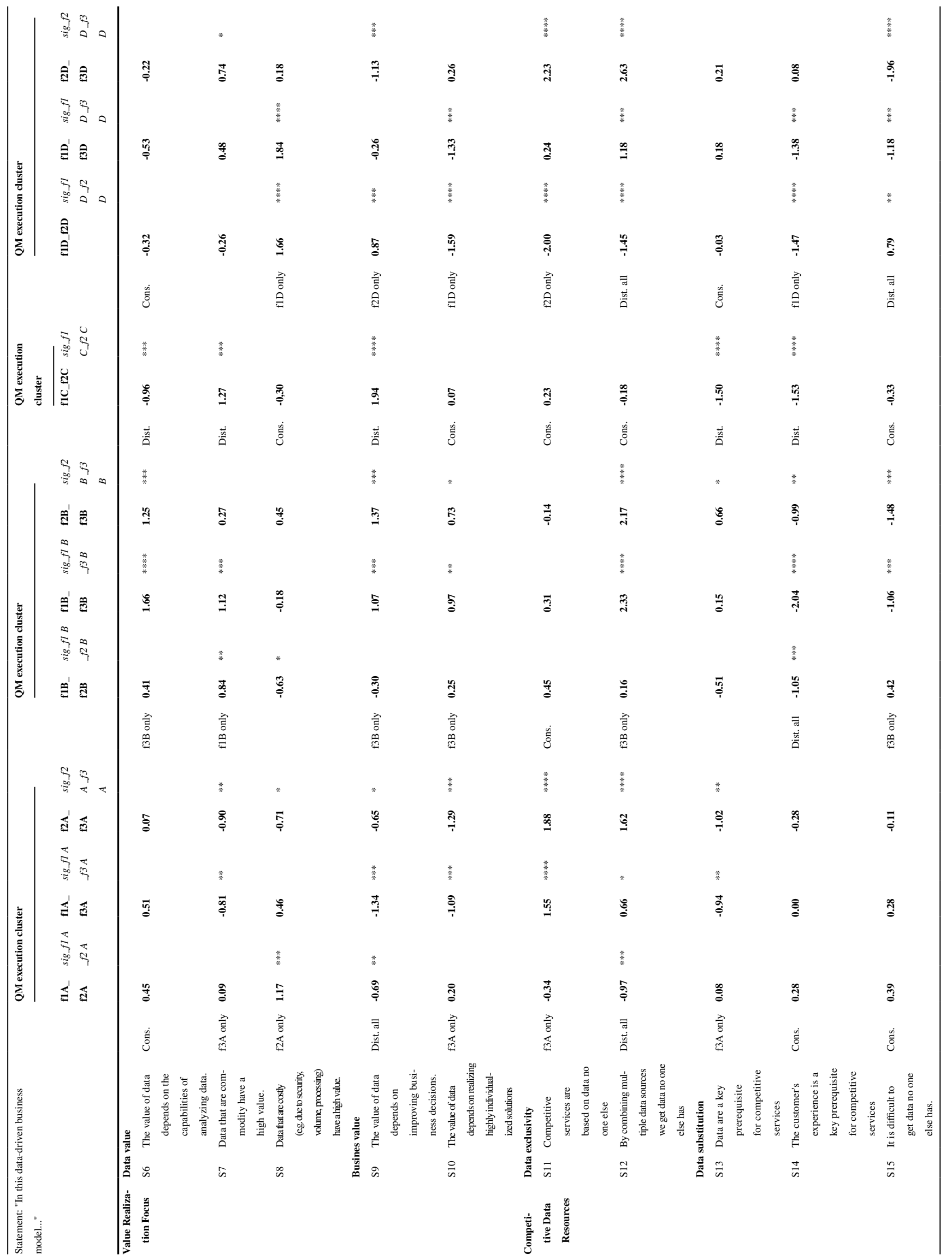


800

M. Förster et al.

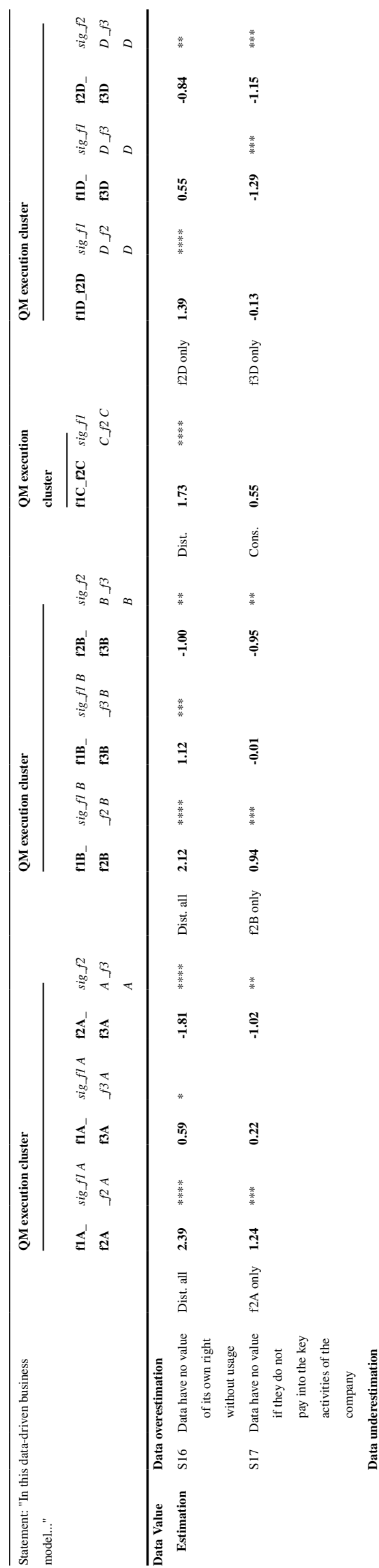

(n) Springer

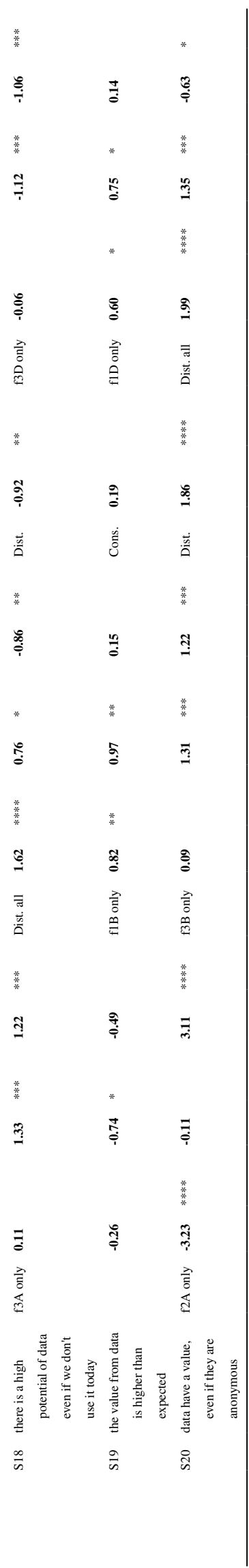




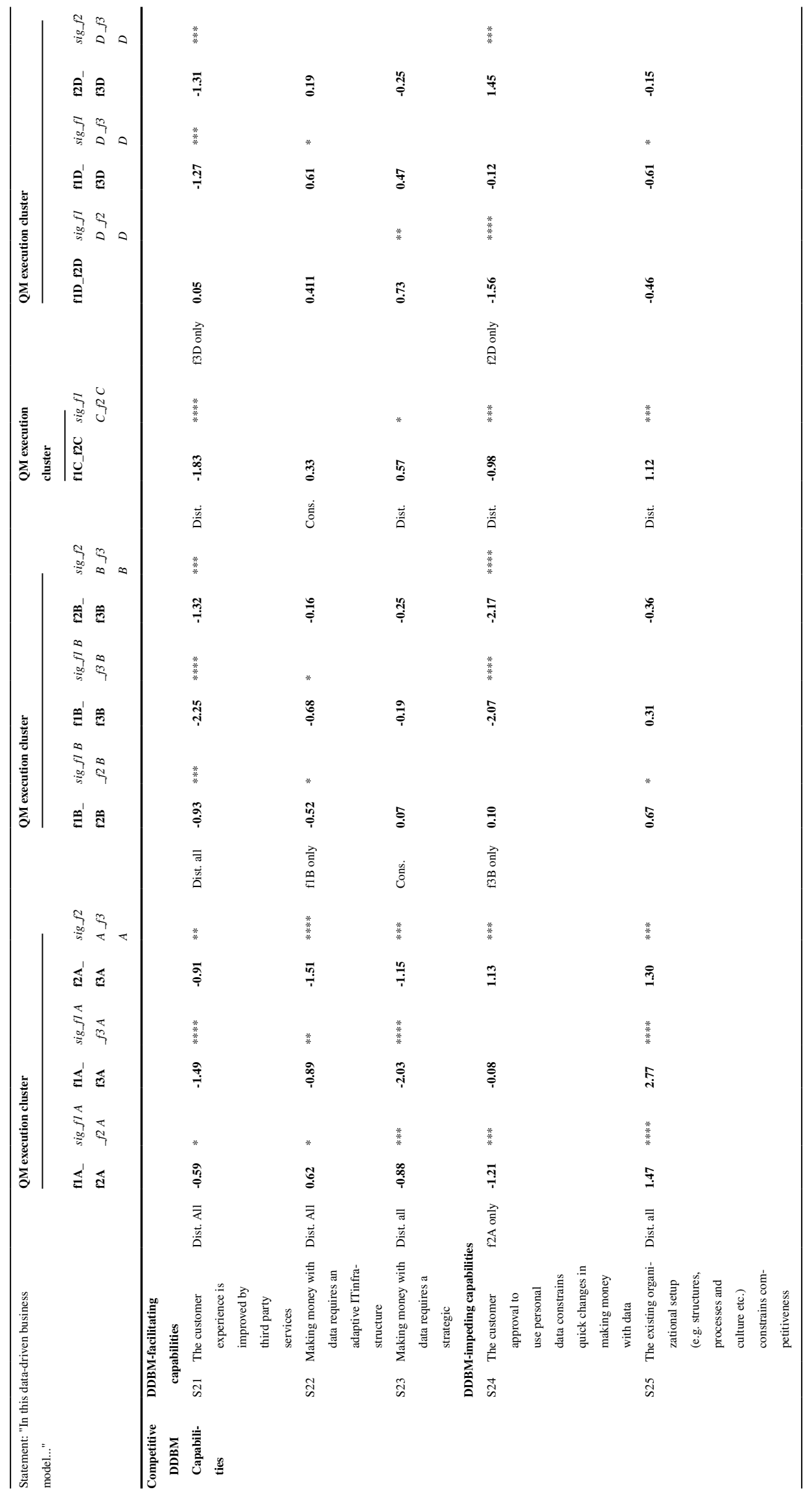


Funding Open Access funding enabled and organized by Projekt DEAL.

Open Access This article is licensed under a Creative Commons Attribution 4.0 International License, which permits use, sharing, adaptation, distribution and reproduction in any medium or format, as long as you give appropriate credit to the original author(s) and the source, provide a link to the Creative Commons licence, and indicate if changes were made. The images or other third party material in this article are included in the article's Creative Commons licence, unless indicated otherwise in a credit line to the material. If material is not included in the article's Creative Commons licence and your intended use is not permitted by statutory regulation or exceeds the permitted use, you will need to obtain permission directly from the copyright holder. To view a copy of this licence, visit http://creativecommons.org/licenses/by/4.0/.

\section{References}

Achtenhagen, L., Melin, L., \& Naldi, L. (2013). Dynamics of business models: Strategizing, critical capabilities and activities for sustained value creation. Long Range Planning, 46(6), 427-442. https://doi.org/10.1016/j.lrp.2013.04.002

Afuah, A., \& Tucci, C. (2003). Internet business models and strategies: Text and cases (2nd ed.). McGraw Hill.

Akred, J., \& Samani, A. (2018). Your data is worth more than you think. In MIT Sloan Management Review. Available online at https://sloanreview.mit.edu/article/your-datais-worth-more-thanyou-think/. Accessed 11/12/2021

Akter, S., \& Wamba, S. F. (2016). Big data analytics in E-commerce: A systematic review and agenda for future research. Electronic Markets, 26(2), 173-194. https://doi.org/10.1007/ s12525-016-0219-0

Al-Debei, M. M., El-Haddadeh, \& Avison, D. (2008). Defining the business model in the new world of digital business. AMCIS 2008 Proceedings (pp. 300-311)

Alfaro, E., Bressan, M., Girardin, F., Murillo, J., Someh, I., \& Wixom, B. H. (2019). BBVA's data monetization journey. MIS Quarterly Executive. https://doi.org/10.17705/2msqe.00011

Andria, G., Attivissimo, F., Di Nisio, A., Lanzolla, A., \& Pellegrino, A. (2016). Development of an automotive data acquisition platform for analysis of driving behavior. Measurement, 93, 278-287. https://doi.org/10.1016/j.measurement.2016.07.035

Baldassarre, M. T., Caballero, I., Caivano, D., Rivas Garcia, B., \& Piattini, M. (2018). From big data to smart data: A data quality perspective. Proceedings of the 1st ACM SIGSOFT International Workshop on Ensemble-Based Software Engineering, 1, 19-24.

Bärenfanger, R., \& Otto, B. (2015). Proposing a capability perspective on digital business models. Proceedings of the 7th IEEE Conference on Business Informatics, 7, 17-25. https://doi.org/ 10.1109/CBI.2015.18

Barnes, C., Blake, H., \& Pinder, D. (2009). Creating \& delivering your value proposition: Managing customer experience for profit. Kogan Page.

Beath, C. M., Becerra-Ferernandez, I., Ross, J. W., \& Short, J. (2012). Finding value in the information explosion. MIT Sloan Management Review, 53(4), 471-482.

Becker, T. (2016). Big data usage. In J. M. Cavanillas, E. Curry, \& W. Wahlster (Eds.), New horizons for a data-driven economy. A roadmap for usage and exploitation of big data in Europe (pp. 143-168). Springer International Publishing.

Bhimani, A. (2015). Exploring big data's strategic consequences. Journal of Information Technology, 30(1), 66-69.
Bittner, E. A. C., \& Leimeister, J. M. (2014). Creating shared understanding in heterogeneous work groups: Why it matters and how to achieve it. Journal of Management Information Systems, 31(1), 111-144. https://doi.org/10.2753/MIS0742-1222310106

Böhmecke-Schwafert, M., \& Niebel, C. (2018). The general data protection's (GDPR) impact on data-driven business models: The case of the right to data portability and facebook. International Telecommunication Union Journal ICT Discoveries (2). Available online at https://www.itu.int/en/journal/002/Documents/ ITU2018-2.pdf. Accessed 11/12/2021

Bolognini, L., \& Bistolfi, C. (2017). Pseudonymization and impacts of big (personal/anonymous) data processing in the transition from the directive 95/46/EC to the new EU general data protection regulation. Computer Law \& Security Review, 33(2), 171-181. https://doi.org/10.1016/j.clsr.2016.11.002

Breitfuß, G., Fruhwirth, M., Pammer-Schindler, V., Stern, H., \& Dennerlein, S. (2019). The data-driven business value matrix: A classification scheme for data-driven business models. Proceedings of the 32nd Bled eConference

Bridoux, F., Coeurderoy, R., \& Durand, R. (2011). Heterogenous motives and the collective creation of value. Academy of Management Review, 36(4), 711-730. https://doi.org/10.5465/AMR. 2011.65554704

Bridoux, F., \& Stoelhorst, J. W. (2014). Microfoundations for stakeholder theory: Managing stakeholders with heterogeneous motives. Strategic Management Journal, 35(1), 107-125. https:// doi.org/10.1002/smj.2089

Brown, S. R. (1980). Political subjectivity: applications of Q methodology in political science. Yale University Press.

Brownlow, J., Zaki, M., Neely, A., \& Urmetzer, F. (2015). Data and analytics - data-driven business models: A blueprint for innovation. Cambridge Service Alliance.

Bulger, M., Taylor, G., \& Schroeder, R. (2014). Data-driven business models: Challenges and opportunities of big data. University of Oxford.

Chasin, F., Paukstadt, U., Ullmeyer, P., \& Becker, J. (2020). Creating value from energy data: A practitioner's perspective on datadriven smart energy business models. Schmalenbach Business Review. https://doi.org/10.1007/s41464-020-00102-1

Cheah, S., \& Wang, S. (2017). Big data-driven business model innovation by traditional industries in the Chinese economy. Journal of Chinese Economic and Foreign Trade Studies, 10(3), 229-251. https://doi.org/10.1108/JCEFTS-05-2017-0013

Chen, H., Chiang, R. H. L., \& Storey, V. C. (2012). Business intelligence and analytics: From big data to big impact. MIS Quarterly, 36(4), 1165-1188.

Choi, Y. R., \& Shepherd, D. A. (2005). Stakeholder perceptions of age and other dimensions of newness. Journal of Management, 31(4), 573-596. https://doi.org/10.1177/0149206304272294

Clemons, E. K. (2009). Business models for monetizing internet applications and web sites: Experience, theory, and predictions. Journal of Management Information Systems, 26(2), 15-41. https:// doi.org/10.2753/MIS0742-1222260202

Court, D. (2015). Getting big impact from big data. McKinsey Quarterly, 1, 52-60.

Crane, A., \& Matten, D. (2004). Business ethics: Managing corporate citizenship and sustainability in the age of globalization (Fourth edition, impression: 2). Oxford University Press.

Cross, R. M. (2005). Exploring attitudes: The case for Q methodology. Health Education Research, 20(2), 206-213. https://doi.org/10. 1093/her/cyg 121

Donaldson, T., \& Preston, L. E. (1995). The stakeholder theory of the corporation: Concepts, evidence, and implications. The Academy of Management Review, 20, 65-91. 
Duch-Brown, N., Martens, B., \& Mueller-Langer, F. (2017). The economics of ownership, access and trade in digital data. SSRN Electronic Journal. https://doi.org/10.2139/ssrn.2914144

El Sawy, O. A., \& Pereira, F. (2013). Business modelling in the dynamic digital space. Springer.

Engels, B. (2019). An unknown treasure: How do companies determine the value of their data. Global Economic Observer, 7(1), 41-49.

Exner, K., Stark, R., \& Kim, J. Y. (2017). Data-driven business model a methodology to develop smart services. Proceedings of the $23 \mathrm{rd}$ International Conference on Engineering, Technology and Innovaiton, 23, 146-154. https://doi.org/10.1109/ICE.2017.8279882

Fielt, E., Desouza, K. C., Gable, G., \& Westerveld, P. (2019). Datadriven business models and professional services firms: A strategic framework and transitionary pathways. In J. J. Xu, B. Zhu, X. Liu, M. J. Shaw, H. Zhang, \& M. Fan (Eds.), Lecture notes in business information processing. The ecosystem of e-Business: Technologies, stakeholders, and connections (pp. 26-38). Springer International Publishing.

Flick, U. (2011). Triangulation. In G. Oelerich \& H.-U. Otto (Eds.), Empirische Forschung und Soziale Arbeit (pp. 323-328). VS Verlag für Sozialwissenschaften.

Förster, M., Bansemir, B., \& Roth, A. (2019). Understanding the role of data for innovating business models: A system dynamics perspective. Proceedings of the 14th International Conference on Wirtschaftsinformatik, 14(1), 1739-1753.

Förster, M., Bansemir, B., \& Roth, A. (2021). Innovation von datengetriebenen Geschäftsmodellen: Oft probiert, häufig gescheitert? Ein Vorgehensmodell zur Wertrealisierung von Daten. HMD Praxis der Wirtschaftsinformatik. https://doi.org/ 10.1365/s40702-021-00730-2

Foster, D., \& Jonker, J. (2005). Stakeholder relationships: The dialogue of engagement. Corporate Governance: The International Journal of Business in Society, 5(5), 51-57. https://doi.org/10.1108/ 14720700510630059

Freeman, R. E. (1984). Strategic management: A stakeholder approach. Pitman series in business and public policy. Pitman.

Freeman, R. E. (2010). Managing for stakeholders: Trade-offs or value creation. Journal of Business Ethics, 96, 7-9. https://doi.org/10. 2139/ssrn. 1182862

Freudenreich, B., Lüdeke-Freund, F., \& Schaltegger, S. (2019). A stakeholder theory perspective on business models: Value creation for sustainability. Journal of Business Ethics. https://doi.org/ 10.1007/s10551-019-04112-z

Fruhwirth, M., Breitfuß, G., \& Pammer-Schindler, V. (2018). Exploring challenges in data-driven business model innovation from Austrian enterprises. Proceedings of the 29th ISPIM Innovation Conference

Fruhwirth, M., Pammer-Schindler, V., \& Thalmann, S. (2019). To sell or not to sell: Knowledge risks in data-driven business models. Proceedings of the 2019 Pre-ICIS SIGDSA Symposium

Fruhwirth, M., Rachinger, M., \& Prlja, E. (2020a). Discovering business models of data marketplaces. Proceedings of the $23 \mathrm{rd}$ Hawaii International Conference onm Information System Sciences, 53, 5738-5747. https://doi.org/10.24251/HICSS.2020.704

Fruhwirth, M., Ropposch, C., Pammer-Schindler, V., \& Ropposch, C. (2020b). Supporting data-drive business model innovations: A structured literature review on tools and methods. Journal of Business Models, 8(1), 7-25. https://doi.org/10.5278/ojs.jbm. v8i1.3529

Garriga, E. (2014). Beyond stakeholder utility function: Stakeholder capability in the value creation process. Journal of Business Ethics, 120(4), 489-507. https://doi.org/10.1007/s10551-013-2001-y

Gassmann, O., Frankenberger, K., \& Sauer, R. (2016). Exploring the field of business model innovation: New theortical perspectives. Springer International Publishing.
Ghoshal, A., Larson, Eric C., Subramanyam, Ramanath, \& Shaw, M. J. (2014). The impact of business analytics strategy on social, mobile, and cloud computing adoption. Proceedings of the 35th International Conference on Information Systems

Gioia, D. A., Corley, K. G., \& Hamilton, A. L. (2012). Seeking qualitative rigor in inductive research. Organizational Research Methods, 16(1), 15-31. https://doi.org/10.1177/1094428112452151

Greenwood, M. R., \& Anderson, E. (2009). 'I used to be an employee but now I am a stakeholder': Implications of labelling employees as stakeholders. Asia Pacific Journal of Human Resources, 47(2), 186-200. https://doi.org/10.1177/1038411109105441

Grieger, M., \& Ludwig, A. (2019). On the move towards customercentric business models in the automotive industry-a conceptual reference framework of shared automotive service systems. Electronic Markets, 29(3), 473-500. https://doi.org/10.1007/ s12525-018-0321-6

Grover, V., Chiang, R. H., Liang, T.-P., \& Zhang, D. (2018). Creating strategic business value from big data analytics: A research framework. Journal of Management Information Systems, 35(2), 388-423. https://doi.org/10.1080/07421222.2018.1451951

Guggenberger, T., Möller, F., Boualouch, K., \& Otto, B. (2020). Towards a Unifying Understanding of Digital Business Models. Proceedings of the 23rd Pacific Asia Conference on Information Systems.

Günther, W., Mehrizi, M. H. R., Huysman, M., \& Feldberg, F. (2017a). Rushing for gold: Tensions in creating and appropriating value from big data. Proceedings of the 38th International Conference on Information Systems.

Günther, W. A., Mehrizi, M. H. R., Huysman, M., \& Feldberg, F. (2017b). Debating big data: A literature review on realizing value from big data. The Journal of Strategic Information Systems, 26(3), 191-209. https://doi.org/10.1016/j.jsis.2017.07.003.

Hagiu, A., \& Wright, J. (2020). When data creates competitive advantage, and when it doesn't. Harvard Business Review, 98, 94-101.

Halis, M., \& Gökgöz. . (2007). Creating organizational commitment by satisfying internal customers. Serbian Journal of Management, 2(1), 5-19.

Halsam, C., Tsitsianis, N., Andersson, T., \& Gleadle, P. (2015). Accounting for business models: Increasing the visibility of stakeholders. Journal of Business Models, 3(1), 62-80.

Hanelt, A., Piccinini, E., Gregory, R. W., Hildebrandt, B., \& Lutz, M. K. (2015). Digital transformation of primarily phyisical industries: Exploring the impact of digital trends on business models of automobile manufacturers. Proceedings of the 12th International Conference on Wirtschaftsinformatik, 12(1), 1313-1327.

Harris, J. G. (2012). Data is useless without the skills to analyze it. Harvard Business Review, 90, 13.

Harrison, J. S., Bosse, D. A., \& Phillips, R. A. (2010). Managing for stakeholders, stakeholder utility functions and competitive advantage. Strategic Management Journal, 31, 58-74.

Hartmann, P. M., Zaki, M., Feldmann, N., \& Neely, A. (2016). Capturing value from big data: A taxonomy of data-driven business models used by start-up firms. International Journal of Operations \& Production Management, 36(10), 1382-1406. https://doi. org/10.1108/IJOPM-02-2014-0098

Hilbig, R., Hecht, S., \& Etsiwah, B. (2020). The rise of data-driven business models in the berlin start-up scene. In P. J. Barlatier \& A. L. Mention (Eds.), Open innovation: Bridging theory and practice. Managing digital open innovation (pp. 353-377). World Scientific.

Huang, H.-C., Lai, M.-C., Lin, L.-H., \& Chen, C.-T. (2013). Overcoming organizational inertia to strengthen business model innovation. Journal of Organizational Change Management, 26(6), 977-1002. https://doi.org/10.1108/JOCM-04-2012-0047 
Jones, T. M. (1995). Instrumental stakeholder theory: A synthesis of ethics and economics. Academy of Management Review, 20(2), 404-437.

Jones, T. M., \& Wicks, A. C. (1999). Convergent stakeholder theory. Academy of Management Review, 24(2), 206-221. https://doi. org/10.5465/amr.1999.1893929

Joyce, A., \& Paquin, R. L. (2016). The triple layered business model canvas: A tool to design more sustainable business models. Journal of Cleaner Production, 135, 1474-1486. https://doi.org/10. 1016/j.jclepro.2016.06.067

Kannan, K., Ananthanarayanan, R., \& Mehta, S. (2018). What is my data worth? From data properties to data value. Retrieved from http://arxiv.org/pdf/1811.04665v1. Accessed 20 July 2020.

Kelley, T., \& Littman, J. (2005). The ten faces of innovation: IDEO's strategies for beating the devil's advocate \& driving creativity throughout your organization. New York: Currency/Doubleday. Retrieved from http://www.tenfacesofinnovation.com. Accessed 07 Aug 2020.

Kerber, W. (2019). Data-sharing in IoT ecosystems: From a competition law perspective: The example of connected cars. SSRN Electronic Journal. https://doi.org/10.2139/ssrn.3445422

Khurshid, M. M., Zakaria, N. H., \& Rashid, A. (2017). Big data value dimensions in food disaster domain. Journal of Information Systems Research and Innovation, 11(1), 25-29.

Köster, O. (2021). Legal evaluation of monetizing automotive data. In T. Bertram (Ed.), Proceedings. Automatisiertes Fahren 2020 (pp. 77-89). Springer.

Koutroumpis, P., Leiponen, A., \& Thomas, L. D. W. (2020). Markets for data. Industrial and Corporate Change. https://doi.org/10. 1093/icc/dtaa002

Krčo, S., van Kranenburg, R., Lončar, M., Ziouvelou, X., \& McGroarty, F. (2019). Digitization of value chains and ecosystems. In A. Aagaard (Ed.), Digital business models (pp. 81-116). Springer International Publishing.

Kringelum, L. B. (2015). A cognitive perspective on the antecedents of business model innovation: The case of the Port of Aalborg Authority. Proceedings of the DRUID Academy conference

Kugler, L. (2018). The war over the value of personal data. Communications of the ACM, 61(2), 17-19.

Kühne, B., \& Böhmann, T. (2019). Data-driven business models: Building the bridge between data and value. Proceedings of the 27th European Conference on Infromation Systems (ECIS2019)

Lambrecht, A., \& Tucker, C. E. (2015). Can big data protect a firm from competition? SRN Electronic Journal. https://doi.org/10. 2139/ssrn.2705530

Lucas, H. C., \& Goh, J. M. (2009). Disruptive technology: How Kodak missed the digital photography revolution. Journal of Strategic Information Systems, 18(1), 46-55. https://doi.org/10.1016/j.jsis. 2009.01.002

Malgieri, G., \& Custers, B. (2018). Pricing privacy: The right to know the value of your personal data. Computer Law \& Security Review, 34(2), 289-303. https://doi.org/10.1016/j.clsr.2017.08. 006

Maltby, J., \& Wilkinson, R. (1998). Stakeholding and corporate governance in the UK. Politics, 18(3), 197-204. https://doi.org/10. 1111/1467-9256.00078

Manyika, J., Chui, M., Brown, B., Bughin, J., Robbs, R., Roxburgh, C., \& Byers, A. H. (2011). Big data. The next frontier for innovation, competition and productivity. Retrieved from https://bigda tawg.nist.gov/pdf/MGI_big_data_full_report.pdf. Accessed 30 Oct 2017.

Mazur, K. E., \& Asah, S. T. (2013). Clarifying standpoints in the gray wolf recovery conflict: Procuring management and policy forethought. Biological Conservation, 167, 79-89. https://doi.org/ 10.1016/j.biocon.2013.07.017
McAfee, A., \& Brynjolfsson, E. (2012). Big data: The management revolution. Harvard Business Review, 90(10), 60-68.

McGuire, T., Manyika, J., \& Chui, M. (2012). Why big data is the new competitive advantage. Retrieved from https://iveybusine ssjournal.com/publication/why-big-data-is-the-new-competitiveadvantage/. Accessed 10 June 2020.

Miller, K., McAdam, M., \& McAdam, R. (2014). The changing university business model: A stakeholder perspective. $R \& D$ Management, 44(3), 265-287. https://doi.org/10.1111/radm.12064

Mitchell, D. K., Agle, B. R., \& Wood, D. J. (1997). Toward a theory of stakeholder identification and salience: Defining the principle of who and what really counts. The Academy of Management Review, 22(4), 853-886.

Moellers, T., von der Burg, L., Bansemir, B., Pretzl, M., \& Gassmann, O. (2019). System dynamics for corporate business model innovation. Electronic Markets, 29(1), 387-406. https://doi.org/10. 1007/s12525-019-00329-y

Mohr, D., Camplone, G., Wee, D., Möller, T., \& Bertoncello, M. (2016). Car data: Paving the way to value-creating mobility: Perspectives on a new automotive business model. Retrieved from https://www.mckinsey.com/ /media/McKinsey/Industries/ Automotive $\% 20$ and $\% 20$ Assembly/Our\%20Insights/Creating\% 20 value $\% 20$ from $\% 20$ car $\% 20$ data/Creating $\% 20$ value $\% 20$ from $\%$ 20car\%20data.ashx. Accessed 15 July 2017.

Möller, F., Stachon, M., Hoffmann, C., Bauhaus, H., \& Otto, B. (2020). Data-driven business models in logistics: A taxonomy of optimization and visibility services. Proceedings of the 53rd Hawaii International Conference on System Sciences, 53, 5379-5388.

Ngai, E. W. T., Gunasekaran, A., Wamba, S. F., Akter, S., \& Dubey, R. (2017). Big data analytics in electronic markets. Electronic Markets, 27(3), 243-245. https://doi.org/10.1007/s12525-017-0261-6

Nolin, J. M. (2019). Data as oil, infrastructure or asset?: Three metaphors of data as economic value. Journal of Information, Communication and Ethics in Society, 18(1), 28-43. https://doi.org/ 10.1108/JICES-04-2019-0044

Opher, A., Chou, A., Onda, A., \& Sounderrajan, K. (2016). The rise of the data economy. Driving value through internet of things data monetization: A perspective for chief digital officers and chief technology officers. IBM Corporation.

Otonomo. (2019). Otonomo dynamic anonymization engine: Intelligently anonymizing car data for more apps and services. Retrieved from https://otonomo.io/wp-content/uploads/2019/ 07/Otonomo-Dynamic-Anonymization-Engine.pdf. Accessed 25 April 2021.

Otto, B. (2015). Quality and value of the data resource in large enterprises. Information Systems Management, 32(3), 234-251. https://doi.org/10.1080/10580530.2015.1044344

Parmar, B. L., Freeman, R. E., Harrison, J. S., Wicks, A. C., Purnell, L., \& de Colle, S. (2010). Stakeholder theory: The state of the art. The Academy of Management Annals, 4(1), 403-445. https:// doi.org/10.1080/19416520.2010.495581

Pevec, D., Vdovic, H., Gace, I., Sabolic, M., Babic, J., \& Podobnik, V. (2019). Distributed data platform for automotive industry: A robust solution for tackling big challenges of big data in transportation science. Proceedings of the 15th International Conference on Telecommunications, $1-8$

Piccinini, E., Hanelt, A., Gregory, R., Gregory, R. W., \& Kolbe, L. M. (2015). transforming industrial business: The impact of digital transformation on automotive organizations. Proceedings of the 36th International Conference on Information Systems, 36(1)

Pynnönen, M., Hallikas, J., \& Ritala, P. (2012). Managing customerdriven business model innovation. International Journal of Innovation Management, 16(04), 1250022. https://doi.org/10.1142/ S1363919612003836 
Ramlo, S. E., \& Newman, I. (2011). Q Methodology and its position in the mixed-methods continuum. Operant Subjectivity-The International Journal of Q Methodology, 34(3), 172-191.

Ransbotham, S., Kiron, D., Prentice, P., \& K. . (2016). Beyond the hype: The hard work behind analytics success. MIT Sloan Management Review, 57(3), 3-16.

Redman, T. C. (2008). Data driven: Profiting from your most important business asset. Harvard Business School Publishing.

Ross, J. W., Beath, C. M., \& Quaadgras, A. (2013). You may not need big data after all. Harvard Business Review, 91(12), 90-98.

Schallmo, D., Williams, C. A., \& Boardman, L. (2017). Digital transformation of business models: Best practices, enablers, and roadmap. International Journal of Innovation Management, 21(08), 1740014. https://doi.org/10.1142/S136391961740014X

Schroeder, R. (2016). Big data business models: Challenges and opportunities. Cogent Social Sciences. https://doi.org/10.1080/23311 886.2016.1166924

Schüritz, R., \& Satzger, G. (2016). Patterns of data-infused business model innovation. 18th IEEE Conference on Business Informatics, 18

Schüritz, R., Seebacher, S., \& Dorner, R. (2017). Capturing value from data: Revenue models for data-driven services. Proceedings of the 50th Hawaii International Conference on System Sciences, $50,5348-5357$

Schwarzkopf, D. L. (2006). Stakeholder perspectives and business risk perception. Journal of Business Ethics, 64(4), 327-342. https:// doi.org/10.1007/s10551-006-0002-9

Schymanietz, M., \& Jonas, J. M. (2020). The roles of individual actors in data-driven service innovation: A dynamic capabilities perspective to explore its microfoundations. Proceedings of the 53rd Hawaii International Conference on System Sciences, 53, $1135-1144$

Seddon, P. B., Constantinidis, D., Tamm, T., \& Dod, H. (2017). How does business analytics contribute to business value? Information Systems Journal, 27(3), 237-269. https://doi.org/10.1111/ isj. 12101

Seiberth, G., \& Gründinger, W. (2018). Data-driven business models in connected cars, mobility services \& beyond. BVDW Research, $1,18$.

Sell, D. K., \& Brown, S. R. (1984). Q methodology as a bridge between qualitative and quantitative research: Application to the analysis of attitude change in foreign study program participants. In H. J. Vacca \& H. A. Johnson (Eds.), Qualitative research in education (pp. 79-87). Kent State University Press.

Sharma, R., Mithas, S., \& Kankanhalli, A. (2014). Transforming decision-making processes: A research agenda for understanding the impact of business analytics on organisations. European Journal of Information Systems, 23(4), 433-441. https://doi.org/10.1057/ ejis. 2014.17

Smith, D. J. (2013). Power-by-the-hour: The role of technology in reshaping business strategy at Rolls-Royce. Technology Analysis \& Strategic Management, 25(8), 987-1007.

Soley, A. M., Siegel, J. E., Suo, D., \& Sarma, S. E. (2018). Value in vehicles: Economic assessment of automotive data. Digital Policy, Regulation and Governance, 20(6), 513-527. https://doi. org/10.1108/DPRG-05-2018-0025

Sorescu, A., Frambach, R. T., Singh, J., Rangaswamy, A., \& Bridges, C. (2011). Innovations in retail business models. Journal of Retailing, 87(1), S3-S16. https://doi.org/10.1016/j.jretai.2011. 04.005

Spiekermann, M. (2019). Data marketplaces: Trends and monetisation of data goods. Intereconomics, 54(4), 208-216. https://doi.org/ $10.1007 / \mathrm{s} 10272-019-0826-\mathrm{z}$

Stainton Rogers, R. (1995). Q methodology. In J. A. Smith, R. Harre, \& L. van Langenhove (Eds.), Rethinking methods in psychology (pp. 178-192). Sage.
Stephenson, W. (1936). The inverted factor technique. British Journal of Psychology, 26(4), 344-361.

Stephenson, W. (1953). The study of behavior: Q-technique and its methodology. Uiversity of Chicago Press.

The Economist. (2017). The world's most valuable resource is no longer oil, but data: The data economy demands a new approach to antitrust rules. Retrieved from https://www.economist.com/ news/leaders/21721656-data-economy-demands-new-approachantitrust-rules-worlds-most-valuable-resource. Accessed $30 \mathrm{Oct}$ 2020.

Tiefenbacher, K., \& Olbricht, S. (2015). Increasing the level of customer orientation: A big data case study from insurance industry. Proceedings of 23rd European Conference of Information Systems

Tikkanen, H., Lamberg, J.-A., Parvinen, P., \& Kallunki, J.-P. (2005). Managerial cognition, action and the business model of the firm. Management Decision, 43(6), 789-809. https://doi.org/10.1108/ 00251740510603565

Timmers, P. (1998). Business models for electronic markets. Electronic Markets, 8(2), 3-8.

Ugray, Z., Paper, D., \& Johnon, J. (2019). How business value is extracted from operational data. A case study. In A. Aagaard (Ed.), Digital business models (pp. 117-145). Springer International Publishing.

Vanauer, M., Böhle, C. \& Hellingrath, B. (2015). Guiding the introduction of big data in organizations: A methodology with business- and data-driven ideation and enterprise architecture management-based implementation. Proceedings of the 48th Hawaii International Conference on System Sciences, 48, 1530-1605

Wamba, S. F., Akter, S., Edwards, A., Chopin, G., \& Gnanzou, D. (2015). How 'big data' can make big impact: Findings from a systematic review and a longitudinal case study. International Journal of Production Economics., 165, 234-246.

Watts, S., \& Stenner, P. (2003). Q methodology, quantum theory and psychology. Operant Subjectivity, 26(3), 155-173.

Watts, S., \& Stenner, P. (2005). Doing Q methodology: Theory, method and interpretation. Qualitative Research in Psychology, 2(1), 67-91. https://doi.org/10.1191/1478088705qp022oa

Weill, P., \& Woerner, S. L. (2015). Thriving in an increasingly digital ecosystem. MIT Sloan Management Review, 53(4), 27-34.

Weinberger, M., Bilgeri, D., \& Fleisch, E. (2016). IoT business models in an industrial context. At-Automatisierungstechnik, 64(9), 699-706. https://doi.org/10.1515/auto-2016-0054

Wiener, M., Saunders, C., \& Marabelli, M. (2020). Big-data business models: A critical literature review and multiperspective research framework. International Journal of Information Technology, 35(1), 66-91. https://doi.org/10.1177/0268396219896811

Wixom, B. H., \& Ross, J. W. (2017). How to monetize your data. MIT Sloan Management Review, 58(3), 10-13.

Woerner, S. L., \& Wixom, B. H. (2015). Big data: Extending the business strategy toolbox. Journal of Information Technology, 30(1), 60-62. https://doi.org/10.1057/jit.2014.31

Wolfe, R. A., \& Putler, D. S. (2002). How tight are the ties that bind stakeholder groups? Organization Science, 13(1), 64-80. https:// doi.org/10.1287/orsc.13.1.64.544

Zabala, A. (2018). Package 'qmethod': Analysis of subjective perspectives using $Q$ methodology. Retrieved from https://cran.micro soft.com/snapshot/2018-08-02/web/packages/qmethod/qmeth od.pdf. Accessed 18 Aug 2020

Zabala, A. (2014). qmethod: A package to explore human perspectives using Q methodology. The R Journal, 6(2), 163-173.

Zabala, A., Sandbrook, C., \& Mukherjee, N. (2018). When and how to use $\mathrm{Q}$ methodology to understand perspectives in conservation research. Conservation Biology, 32(5), 1185-1194. https://doi. org/10.32614/rj-2014-032 
Zeng, J., \& Glaister, K. W. (2018). Value creation from big data: Looking inside the black box. Strategic Organization, 16(2), 105-140. https://doi.org/10.1177/1476127017697510

Zhang, J. J., Lichtenstein, Y., \& Gander, J. (2015). Designing scalable digital business models. In C. Baden-Fuller \& V. Mangematin (Eds.), Advances in strategic management. Business models and modelling (pp. 241-277). Emerald Group Publishing Limited.

Ziegler, S., Evequoz, E., Huamani, P., \& Anna, M. (2019). The impact of the European general data protection regulation (GDPR) on future data business models: Toward a new paradigm and business opportunities. In A. Aagaard (Ed.), Digital business models (pp. 201-226). Springer International Publishing.
Zolnowski, A., Anke, J., \& Gudat, J. (2017). Towards a Cost-BenefitAnalysis of Data-Driven Business Models. Proceedings of the 13th International Conference on Wirtschaftsinformatik, 13, 181-195.

Zott, C., \& Amit, R. (2010). Business model design: An activity system perspective. Long Range Planning, 43(2-3), 216-226. https:// doi.org/10.1016/j.lrp.2009.07.004

Publisher's Note Springer Nature remains neutral with regard to jurisdictional claims in published maps and institutional affiliations. 